\title{
DYNAMIC SYSTEM PERSPECTIVES ON ANXIETY AND DEPRESSION
}

Bertus F. Jeronimus ${ }^{1,2 *}$

${ }^{1}$ Department of Developmental Psychology, Faculty of Social and Behavioural sciences, Groningen, University of Groningen, The Netherlands.

${ }^{2}$ Interdisciplinary Center Psychopathology and Emotion regulation (ICPE), Department of Psychiatry, University Medical Center Groningen, University of Groningen, Groningen, The Netherlands

* b.f.jeronimus@rug.nl

Please cite this work as: Jeronimus, B.F. (2019). Dynamic system perspectives on Anxiety and Depression. In book: Psychosocial Development in Adolescence: Insights from the Dynamic Systems Approach (Editors: Kunnen, E.S., de Ruiter, N.M.P., Jeronimus, B.F., van der Gaag, M.A.), chapter 7. London: Routledge Psychology. This author version does not exactly replicate the final version published in the book. It is not the copy of record.

\begin{abstract}
Anxiety and depression disorders are the biggest mental health hazards of our time and in many ways closely related. The first anxiety disorder episodes emerge during childhood, while the first depression episodes more typically emerge in adolescence. Such early episodes are highly predictive for lifespan developments. This chapter reviews literature on dynamic system perspectives on anxiety and depression across scales of temporal resolution, from affect and highly contextualized emotion episodes to more persistent moods that evaluate the world as a whole, and the personality traits anxiety and depression that capture thematic recurrences of feelings, thoughts and behavior along the lifespan and how people talk about themselves. These various processes are intimately connected via their self-organizing and dynamic nature and circular causality, which demonstrates how dynamic system perspectives can help us to understand anxiety and depression across the lifespan.
\end{abstract}


"Sherrington (...) thought that the brain worked like a telegraph system. Freud often compared the brain to hydraulic and electro-magnetic systems. Leibniz compared it to a mill, and I am told the ancient Greeks thought the brain functions like a catapult. At present, obviously, the metaphor is the digital computer."

Searle (1984, p. 44).

Anxiety and depression disorders are the biggest mental health hazards of our time, and first episodes often emerge during childhood and adolescence (Merikangas et al., 2010; Rutter et al., 2011). Children can respond with anxiety to separation, animals, thunder, social situations, dentists, and dreams, among others, and many adolescents experience spells of depressed mood, as these are common and transient distress experiences in response to the major biological, psychological and social transitions that are outlined throughout this book ( $c f$. Rutter et al., 2011; Revonsuo, 2000). At the end of adolescence, about 25\% of the population experienced an anxiety or depression disorder, which is defined by significant suffering and functional impairment (APA, 2013; Beesdo et al., 2009; Merikangas et al., 2010; Rutter et al., 2011).

Many children and early adolescents suffer in silence because their mood disorders go unnoticed (Zahn-Waxler et al., 2000), and many more suffer from high anxiety and depression symptom levels. Childhood disorder episodes are often indicative of lifespan developments, as $75 \%$ recur during adolescence, up to an average of nine separate episodes over their lifespan (Burcusa \& Iacono, 2007; Rutter et al., 2011). Some studies suggests that the majority of the youth who have ever been clinically depressed will be in an episode in any given year over the remainder of their lives (Kessler \& Wang, 2009), although others paint a less gloomy future (Bos et al., 2018; Rottenberg et al., 2018). Nonetheless, most adolescents with a depression also report current or past anxiety disorders, while about a third of the adolescents with anxiety disorders also experience depression (Brady, 1992; Davis et al., 2015).

A central goal of psychiatric research is to better understand anxiety and depression states (Kendler et al., 2011). This chapter illustrates the use of dynamic system perspectives to understand anxiety and depression as experiences that emerge from a system of constituent affective, emotion, and mood components that synchronize across scales of resolution and function as one integrated process that evolves within each of us. In doing so this chapter illustrates how dynamic system perspectives can provide new insights into anxiety and depression, connect various literatures, and point at new angles for future research.

\section{Nested systems}

Anxiety and depression can be defined as emotions that span minutes to days, as mood episodes that can persist over weeks to months, and as part of our personalities, which change along the lifespan, and describe how people navigate the world, define who they are, and talk about themselves. Dynamic system perspectives can increase our understanding of anxiety and depression as multi-component and dynamic processes that continuously change over time and are inherently connected via their self-organizing and dynamic nature and circular causality. 
Moods and personality traits are thought to emerge from interactions between highly variable "microscopic" emotion components (as outlined below), after which these more integrated macroscopic system levels start to structure and constrain our moment-to-moment component experiences top-down (see Table 7.1), resulting in circular causality and increasingly complex and stable affect systems (e.g., Fajkowska, 2015; Granic, 2005; Kendler et al., 2011; Van der Stel, 2009; Van Geert \& Steenbeek, 2005; Wichers et al., 2018; Witherington, 2007).

The functional unity of this multiscale system is often illustrated with the metaphor of emotions as the weather of our lives (e.g., sadness as rain clouds, a cold breeze of fear, and sunshine as joy), and mood and personality as our internal climates (e.g., Liljenström \& Svedin, 2005; Ochsner et al., 2012; Russell, 2017). It may be difficult to forecast daily weather and emotions over more than ten days, as these trajectories are inherently chaotic (i.e., irregular and extremely sensitive to small baseline deviations), but more climatic or "average weather" such as seasons are rather stable, predictable, orderly, and relatively enduring (e.g., Boeing, 2016; Liljenström et al., 2005). The personality traits Anxiety and Depression can be seen as macrolevel attractor basins that calibrate our internal dynamics resulting in less environmental input necessary to move toward specific micro real-time emotional states of anxiety and depression (Jeronimus, 2015; Revelle \& Condon, 2017; Van der Stel, 2009). Below we zoom into each of these component levels and processes in detail.

\section{Affect and emotions: the micro level}

Affect is a continuous hedonic "commentary" on our current state of affairs that naturally infuses our perception as if it were a "sixth sense" that is integrated with other sensory processing and is typically experienced as a property of people or objects to help us navigate our world (Barrett, 2017, 2018; Kahneman \& Egan, 2011; Panksepp \& Biven, 2012; Schwarz, 2010; Slovic et al., 2007). Affects are internal subjective states that are only known to those who have them. Anxiety and depression as emotions refer to discrete snapshots of this continuous stream of affective experience, when a specific context becomes imbued with meaning to instigate a specific action.

Emotions can be defined as (a) intense and transient subjective states that last for seconds up to 72 hours at most (Panksepp \& Biven, 2012; Sonnemans \& Frijda, 1994; Verduyn et al., 2011); which (b) "emerge" in response to specific events or stimuli (extrinsic or intrinsic to the organism); and (c) can be categorized according to their affective valence (from unpleasant to pleasant) and emotional arousal or bodily activation (Anderson \& Adolphs, 2014; Yik et al., 2011; Kuppens et al., 2010; Panksepp \& Biven, 2012). Anxiety and depression are both unpleasant affects, and low positive affect is relatively specific for depression and social anxiety, with anxiety being marked by high physiological arousal and depression by low arousal (Russell, 2003; Watson et al., 2005).

The classical emotion perspective postulated that children are born with abilities to distinguish the primary emotions (e.g., anxiety/fear, depression/sadness, happiness, anger, and disgust) that cover most of our transactions with the world (Darwin, 1872; Russell, 1990). These emotions can be recognized via facial expression, skin color, vocal timbre, gestures, and odor, 
among others (Darwin, 1972; Ekman, 2008; De Waal, 2019; Panksepp et al., 2012). In the classical perspective anxiety and depression were understood as hardwired prototypical adaptive scripts that become activated by a particular class of stimuli (e.g., a threat, obstacle, or loss) to orchestrate psychological changes in feelings and thoughts and activate coordinated thought-action repertoires and goal-oriented behavior, which we evolved to respond quickly and adequately to changes in the environment that might affect our well-being (Damasio et al., 2000; Ortony \& Turner, 1990; Panksepp et al., 2012; Plutchik, 2001; Roseman et al., 1994; Russell, 2017).

The prototypical script for anxiety becomes activated when a threat (stimulus) signals the detection of an ongoing source of danger (cognition) and evokes anxiety or fear (affect) as an impulse to prepare, flee, hide, counterattack, or scream (action) to protect ourselves and reach safety (goal), which may well save our lives. Similarly, instances of depression start with the loss of a valued object or support (stimulus) which indicates abandonment (cognition) and evokes sadness (affect) and an impulse to cry (action) in order to reattach with this lost object (goal), or to save energy and tread carefully until conditions improve, and our needs are met. More complex emotions such as shame or guilt were thought to originate as mixtures of these five basic emotions (Plutchik, 2001; Russell, 1990; 2017; Shaver et al., 1987).

A more dynamically oriented constructivist perspective postulates that anxiety and depression have no single physical form and must be understood as spectra (like colours) or categories of instances (families of functionally related states) that differ in many degrees, qualities, and intensities (see Table 7.2), but share their template - like chairs or cookies - and thus cluster near one another in property space (Barrett, 2017, 2018; Kendler et al., 2011; Posner et al., 2005; Russell, 2003; Salzman \& Fusi, 2010). Instances of anxiety and depression differ between people and within people at different instances and along the lifespan, because each episode is constructed from learned assemblies of bits and pieces of previous experience (i.e., statistical regularities) which form prototypical scripts or cognitive tools to communicate about feelings and to anticipate future events and to deal with them (Barrett, 2017, 2018; Russel, 1990, 2001). Recent emotion theories group the thousands semantic emotion terms we use over up to 27 emotion families including anxiety (nervous), fear (afraid, horror), horror (shock, scared), and depression (sadness), see Table 7.2 (e.g., Cowen et al., 2017; Verduyn et al., 2015; Watson et al., 1988).

Today most theorists argue that the emotions anxiety and depression emerge from the synchronization of various interoceptive, perceptual, cognitive, and motor components that mutually amplify one another until they converge at a dominant emotion state that best fits the specific situational instance in which one finds oneself, and from which a subjective understanding of the situation emerges to potentiate a particular remedy to deal with it (Adolphs, 2003; Anderson \& Adolphs, 2014; Barrett, 2018; Damasio et al., 2000; Lewis, 2000; Scherer, 2009; Tooby \& Cosmides, 2008). Subsequently, these anxiety and depression states influence the way people screen, categorize, and interpret information, decide what is important and valuable, and stimulate rumination, which are all feedback loops that direct the dynamic system towards a stable emotion configuration or attractor (see Chapter 1). Such feedback 
Table 7.1. Hierarchical temporal organization of levels for analysis of distress experiences

\begin{tabular}{|c|c|c|c|c|c|c|}
\hline & \multicolumn{2}{|c|}{ Level of organization } & \multirow{2}{*}{$\begin{array}{l}\text { Time scale } \\
\text { Seconds }\end{array}$} & \multirow{2}{*}{$\begin{array}{l}\text { Concept } \\
\text { Feeling - thoughts }\end{array}$} & \multirow{2}{*}{$\begin{array}{l}\text { Construct } \\
\text { Affect - cognitions }\end{array}$} & \multirow{2}{*}{$\begin{array}{l}\text { Severity } \\
+\end{array}$} \\
\hline & Nano & Moment-to-moment & & & & \\
\hline \multirow[t]{2}{*}{1.} & Micro & Fluctuations & Minutes & Emotions & Anxiety, Sadness, Fear, Anger & + \\
\hline & & Daily - diurnal & Hours & Symptoms & Examples provided in Table 7.3 & ++ \\
\hline \multirow[t]{2}{*}{2.} & Meso & States & Weeks & Moods & Anxiety - depression & ++ \\
\hline & & Episodic & Months & Disorder states & MDD - GAD & ++++ \\
\hline \multirow[t]{4}{*}{3.} & Macro & Dispositions & Years & Temperament & Negative affectivity & ++ \\
\hline & & Lifespan & Decades & Personality & Trait anxiety - trait depression & + \\
\hline & Mega & Generations & Centuries & Culture & \multicolumn{2}{|l|}{ Cultural scrips and norms of reaction } \\
\hline & & Lineage & Millennia & Evolution & \multicolumn{2}{|l|}{ Forces that maintain heritable variation } \\
\hline
\end{tabular}

Note: MDD = major depressive disorder; GAD = Generalized Anxiety Disorder. The micro and meso level are often covered in cross-sectional perspectives (e.g., a point prevalence or frequency at a specific point in time) whereas the macrolevel covers lifespan perspectives and lifetime prevalences. 
loops enable the emotion state to unfold over time periods far beyond the presence of the stimuli that caused the emotion and the component processes themselves (called "hysteresis"), a nonlinearity that is typical for complex systems (e.g., Hollenstein, 2015; Verduyn et al., 2015; Van der Maas \& Molenaar, 1992).

This complex emotion system is favored by natural selection because it can reconfigure itself into a multitude of different states while dissimilar representations can give rise to emotion instances of the same category (such as anxiety or depression) in different contexts (Barrett, 2017; Kuppens et al., 2010). Anxiety and depression are thus understood as self-organizing dynamic processes that combine affect, motivation, evaluation, attention, learning, memory, wanting, and so on, to construct emotional experiences that give meaning to context. Because every instance of anxiety or depression is constructed, variability is the norm, which enables individuals to respond flexibly, and to establish unique individual-environment relationships ( Hollenstein, 2015; Scherer, 2009; Tooby \& Cosmides, 2008; Kuppens et al., 2009).

Emotions are multifaceted phenomena that can differ markedly across individuals and cultures, which illustrates their developmental malleability, and each individual should therefore be pictured as a dynamic system with an unique architecture and resulting dynamics over time (Barrett, 2018; Fisher et al., 2018; Fogel et al., 1992; Thompson, 1994). Consequently, two people can experience an identical situation quite differently, and converge to different emotion states (e.g., sad versus anxious) as a consequence of their personal history and situational understanding, including whether the event was unexpected, controllable, can be coped with, was one's own fault, and so on (Barrett, 2017, 2018; Jeronimus et al., 2017, 2019; Stanton, 2012). Individual differences in emotional clarity or the extent into which one can identify, label, and characterize emotions, can explain why some adolescents recognize and experience anxiety and depression as strongly differentiated and discrete emotion states, while others experience either both together or none (Bailen et al., 2019; Erbas et al., 2014; Fisher et al., 2018; Gohm \& Clore, 2000; Mathews et al., 2016).

Adolescents learn to construct and differentiate increasingly fine-tuned feelings as specific emotion categories to summarize experiences more efficiently and precisely, thus increasing emotional granularity or "emotional intelligence" (see Table 7.2; Barrett, 2018; Erbas et al., 2014; Nook et al., 2018; Russell, 1990). Adolescents with heightened interoception and low emotional clarity (i.e., difficulties in attributing these inner sensations to specific emotions) or low granularity (i.e., little emotion differentiation) more often feel unhappy, report social problems, and develop anxiety and depression disorders (Barrett, 2018; Demiralp et al., 2012; Erbas et al., 2014; Kashdan \& Farmer, 2014; Mathews et al., 2016; Palser et al., 2018; Sendzik et al., 2017). Being able to put a feeling into words (such as sad or afraid) can already decrease the subjective intensity of the experience (Lieberman et al., 2011).

An improved understanding of how adolescents construct anxiety and depression and accept these experiences can result in strategies to intervene in this construction process, to buffer adolescents against all kinds of social and mental adversity, as emotions can be deconstructed into their experiential components to be re-categorized, which is thought to 
influence how adolescents perceive their reality (Barrett, 2018; Brackett et al., 2012; Kashdan et al., 2015; Sendzik et al., 2017). Now that we have defined anxiety and depression as prototypical emotion categories (i.e., populations of diverse instances) that emerge in response to specific contexts to give the ebb and flow of life meaning, we zoom into their dynamics.

Table 7.2. Anxiety and depression as emotions and personality traits

\begin{tabular}{|c|c|c|c|}
\hline & \multicolumn{2}{|l|}{ Category } & \multirow{2}{*}{$\begin{array}{l}\text { Instances / definitions } \\
\text { Tense, apprehension, worry, distress, dread, unease, } \\
\text { distressed, frustrated, nervousness, etc. }\end{array}$} \\
\hline \multirow[t]{7}{*}{ Emotions } & Anxiety & Nervous & \\
\hline & Fear & Afraid & $\begin{array}{l}\text { Alarm, fright, terror, panic, hysteria, horror, shock, } \\
\text { mortification, scared, etc. }\end{array}$ \\
\hline & & Horror & Shock, scared \\
\hline & Depression & Sadness & $\begin{array}{l}\text { Gloomy, sorrow, grief, despair, hopeless, misery, } \\
\text { melancholy, bored, droopy, tired, sleepy }\end{array}$ \\
\hline & & & Disappointment, displeasure, dismay \\
\hline & & & Guilt, shame, embarrassment, regret, remorse \\
\hline & & & $\begin{array}{l}\text { Neglect, loneliness, isolation, defeat, rejection, } \\
\text { humiliation, insecurity, homesickness, etc. }\end{array}$ \\
\hline
\end{tabular}

Personality Neuroticism Tendency to perceive the world as threatening, to be prone to experience unpleasant and disturbing emotions in reaction to various types of stress (emotional instability), and to select oneself into situations that foster negative affect.

Anxiety Characteristic level of free floating anxiety and fear proneness

Depression Tendency to experience feelings of sadness, guilt, loneliness, and hopelessness

Note: William James (1890) already emphasized the tremendous variability in the human emotions that people refer to with the same emotion word. Source: The depicted emotion instances were derived from Barrett (2018), Cowen et al. (2017), Russell (1980), and Shaver et al. (1987). The description of neuroticism was derived from Jeronimus (2015) and the definition of the facet traits anxiety and depression from Costa and McCrae (2006).

\section{Dynamic processes}

One of the most challenging topics in the study of anxiety and depression is to understand the processes underlying the temporal dynamics of emotion (Hollenstein, 2015; Houben et al., 2015; Kuppens et al., 2010; Lewis, 2005; Reitsema et al., 2019). The duration of emotions can help to distinguish closely related experiences such as shame versus guilt or fear versus anxiety (Panksepp \& Biven, 2012). For example, when studying 27 emotions, in most people sadness lasted the longest (median 48 hours), while anxiety and guilt (median 4 hours) and fear (median 1 hour) and shame (median 30 minutes) were among the shortest emotion episodes (Verduyn et al., 2015). The most studied emotion dynamics in adolescents include the frequency with which they experience anxiety or depression over a protracted period of time, the average magnitude of emotion over time (intensity), the range of fluctuations (variability), the magnitude of these fluctuations from moment to moment (instability), the temporal dependency or persistence of emotion states (inertia), whether anxiety or depression increase (augment) or decrease (blunt) one another over time, and adolescents' differentiation (granularity) and clarity of emotions (see Bailen et al., 2019 and Reitsema et al., 2019 for reviews). 
Adolescents show substantial individual differences in the dynamics of anxiety and depression, but the average frequencies and intensities peak in late adolescence, especially in girls, followed by a decrease over adulthood (Bailen et al., 2019; Carstensen et al., 2000; Reitsema et al., 2019; see for adults Fisher et al., 2017, 2018; Houben et al., 2015). Adolescents who report more frequent, intense, persistent, and variable negative emotions (especially sadness, nervousness and anger) and decreased positive emotions and energy are most vulnerable for the development of episodes of anxious or depressed mood (Bailen et al., 2019; Kuppens et al., 2012; Neumann et al., 2011; Silk et al., 2003; Morgan et al., 2017).

Today there is a scarcity of studies of real-time (moment-to-moment) dynamics of affect and emotion components and regulation processes in single individuals across and within time under natural conditions in daily life (Hollenstein, 2015; Houben et al., 2015; Wichers et al., 2015, 2018), or how these emotional experiences change over adolescence (see for reviews: Bailen et al., 2019; Reitsema et al., 2019). Momentary assessment studies (EMA) of emotions typically apply non-adjacent sampling intervals and 3 to 10 assessments per day for 7 to 30 days (Houben et al., 2015; Kuppens \& Verduyn, 2017; Reitsema et al., 2019; Trull et al., 2015; Van der Krieke et al., 2015); although some studies assessed daily anxiety symptoms over 236 days (Hoenders et al., 2012) or daily depression symptoms over 239 days (Wichers et al., 2016), and there are studies in which a group completed 500 measures per participant over 4 months (Wichers et al., 2018). Researchers suggest that minimal 25 to 30 assessments per subject may be recommended for multilevel models (Bolger et al., 2012; Maas \& Hox, 2005; which still mix within- and between-person effects), whereas for subject-specific dynamic models of interacting variables by means of vector autoregressive (VAR) modeling at least 44-50 assessments are required (Box et al., 2015; Fisher et al, 2018; Van der Krieke et al., 2016) up to 100 assessments to model changes in the conventional dynamic processes themselves (Bringmann et al., 2017; Wichers et al., 2018) and switches in state-space models (Hamaker \& Grasman, 2012).

Promising future avenues to improve our understanding of anxiety and depression as emotion states are challenging studies that (a) examine various dynamic processes in single adolescents and changes therein over adolescence (Bailen et al., 2019; Reitsema et al., 2019; Koval et al., 2013; Krone et al., 2018) and (b) capture the stream of affective experience in real time to follow their emergence and unfolding via the synchronization of various emotion components (time-shifting contemporaneous relations), which requires high-frequency sampling. Furthermore, dynamic system perspectives can also help to zoom into instances in which emotions fail to function properly, such as disruptions in affective valence or emotional intensity, and problems with emotional clarity and differentiation (APA, 2013; Sendzik et al., 2017). Examples of emotion intensity disturbances include being over- or under-reactive to emotional situations, such as extremely low levels of positive affect in depressed adolescents, or a swing towards extreme high positive affect intensities during manic-depressive episodes (Birmaher, 2013; Rutter et al., 2011). Finally, future studies may use multimethod assessments to capture adolescent experience, and compare and combine different indices for emotion dynamics (Bos et al., 2018; Houben et al., 2015; Koval et al., 2013; Reitsema et al., 2019). 
The emotion literature suggests that (a) anxiety and depression are constructions of the world rather than reactions to it, (b) that changes in emotion dynamics can be indicative for the development of a mood disorder, and (c) may serve as an early warning signal, and these ideas shall be explored in more depth below.

\section{Mood episodes (meso level)}

Anxious and depressed mood spells describe sustained negative background affects that color as generalized emotions but are much lower in arousal and wider in scope. Whereas emotions are highly contextualized, moods evaluate the world as a whole, and often lack a specific start and stop (Barrett, 2018; Beedie et al., 2005; Horwitz \& Wakefield, 2007). Moods can be defined as internal subjective states perpetuated by extended cognitive configurations that narrow attention towards ongoing internal processes (see Table 7.3) and a restricted set of interactions and understandings of the surrounding world (APA, 2013; Gotlib \& Joormann, 2010; Isen, 1990). In short, depressed adolescents are characterized by negative views of themselves, the world, and their future, and uncontrollable self-critical cognitions, which impede their ability to generate positive affect (Gotlib \& Joorman, 2010; Rutter et al., 2011). Mood states typically last for weeks to months and have a relatively constant quality even though the state itself is dynamic (Judd et al., 1998; Larsen, 1987), and this progression from normal affect fluctuations to entrenchment is what characterizes mood as a developmental process (De Zwart et al., 2018; Lewis, 2000; Rutter et al., 2011).

Mood episodes are characterized by the emergence of a metacognitive or recursive consciousness (a higher-order mental structure) as individuals can become aware of their internal state as a mode of perception that underlies cognitive decoupling or "head-and-heart splits" (Damasio et al., 2000; Schooler et al., 2011). People disengage their attention from perception (called "perceptual decoupling"), notice the current contents of consciousness (i.e. meta-awareness), and realize that their feelings do not match their cognitive evaluation of the situation, thus that something goes awry. Key examples are anhedonia and guilt (see Table 7.3). Anhedonia refers to being unable to feel pleasure in situations or after events that one recognizes as normally pleasurable activities, which is typical for childhood depression (see APA, 2013; Russell, 2017). Depressed adolescents often report guilt, a self-conscious emotion characterized by tension, regret, and remorse about a particular (in)action that comprises one's moral or personal standards (i.e. not living up to ideal self) while one could have done otherwise (APA, 2013; Roseman et al., 1994; Rutter et al., 2011). These higher-order mental structures illustrate the complexity of mood states as they emerge from various nonlinear dynamic interactions between affective and cognitive elements.

Anxious and depressed syndromes refer to flexible and dynamic systems of constitutive heterogeneous elements (co-occurring feelings, thoughts, and actions, see Table 7.3 and APA, 2013), thus moods are formative dimensional constructs similar to the constructivist perspective on emotions (e.g., Borsboom, 2008, 2017; Constantini et al., 2019; Fried \& Nesse, 2015; Gotlib \& Joorman, 2010; Heeren et al., 2018; Kendler et al., 2011, 2012; Wichers et al., 2018). There may not even be a classification for anxiety or depression etched in the structure of the world 
and both may be merely concepts (Kendler et al., 2011, 2015). The idea of anxiety and depression as populations of instances and dynamic perspectives on their development can explain how different causes may eventually yield similar symptom clusters while similar causes do not necessarily result in similar outcomes. In a constantly changing world such stable (or inert) anxious or depressed mood states must be maintained with feedback loops that affect the emotional state space by steeping the slopes towards these attractors that previously were passed easily, including cognitive emotion regulation strategies and behaviors (Aldao et al., 2010; Fogel et al., 1992; Granic, 2005; Lewis, 2000; Mathews et al., 2016; Thompson et al., 1994), affective reactivity (e.g., Booij et al., 2018), and feelings of control (e.g., HovenkampHermelink et al., 2019), often in response to stressful experiences (e.g., Jeronimus et al., 2013).

The synchronization of mood elements is typically studied using networks of symptoms (or "nodes") and their interactions (or "connections," see Borsboom 2017; Fried et al., 2017; Marsman et al., 2018; McNally, 2016; Wichers, 2013). The interactions in these systems are described with node centrality indexes, especially connection strength, closeness, and betweenness (Bringmann et al., 2018; McNally, 2016; Opsahl ea, 2010). Strength indicates the direct influence of each symptom or node on the network (via partial correlations), and can be subdivided over instrength (activated by many other symptoms) and outstrength (activates many other symptoms), and node interconnectedness can also be expressed in terms of shared variance with their neighbors (Haslbeck \& Fried, 2017). Closeness indicates the shortest distance between each node to identify direct and indirect influences. Betweenness indicates the number of times a node traverses the shortest path between two other nodes. Nodes with high betweenness are "gate keepers" that connect less central nodes or "bridge" different substructures within the psychological network (see Table 7.3), and because reciprocal symptom connections within and between anxiety and depression are often equivalent (Cramer et al., 2010; Fisher et al., 2017), these experiences frequently co-occur.

Recovery time is a network metric that quantifies emotion regulation efficiency (Thompson, 1994; Yang et al., 2018), and the networks of people with higher overall depression require longer recovery time after socioemotional processes (Yang et al., 2018), also after adjustment for recent life events. High or increasing connectivity between symptoms of affect and cognition may indicate emotional inflexibility or "inertia," which is typically understood as a more fragile system state in which sudden transitions towards other symptom states becomes more likely (Scheffer et al., 2012; Wichers et al., 2018). Adolescents often report sudden changes in symptom levels of anxiety and depression (Rutter et al., 2011), and such transitions are a hallmark of complex systems in which tension may rise gradually (as resilience levels may diminish slowly or even without notice) after which minor contextual disturbances can push the system over a "tipping point" towards another basin of attraction (Callahan et al., 1990; Scheffer et al., 2012; Van der Maas et al., 1992; Wichers et al., 2018).

The concept of an attractor basin can reconcile the common experience of mood states as emerging out of the blue (Hayes et al., 2007) with studies that indicate developmental trajectories for mood symptoms, although discontinuous and non-stationary (Myin-Germeys et al., 2009; Wichers et al., 2018). This dynamic bimodality of normal versus disorder system states is intuitive to many scholars and clinicians and has derived some empirical support (e.g., 
Cramer et al., 2016; Hosenfeld et al., 2015; Van de Leemput et al., 2013). One double-blind study using intensive self-monitoring of one man over 239 days (1474 observations) confirms the presence of a sudden shift in the severity of depressive symptoms (Wichers et al., 2016) and a study over 236 days showed a sharp increase in anxiety symptoms (Hoenders et al., 2012), but such longitudinal evidence remains both scarce and essential (Bos \& De Jonge, 2014). The possibility of discrete shifts between normal versus anxious or depressed states is supported by brain stimulation studies (Panksepp \& Biven, 2012) and rapid shifts from states of anxiety with marked dysphoria to "normal" states of mind after the anxiety-eliciting situation - such as a separation, animal, object, social situation or thunder - is eliminated (Rutter et al., 2011).

Mood symptoms typically develop, activate, and synchronize over time until the system state becomes self-sustaining and unusually intense or persistent (Myin-Germeys et al., 2009; Wichers et al., 2018). For example, insomnia may drive fatigue and concentration problems, while anhedonia may lead to guilt, which may lead to low self-worth, and so on (e.g., Borsboom et al., 2017; Kendler et al., 2011; Wichers et al., 2013). Moods themselves are defined in terms of symptoms that persist over weeks (APA, 2013, macro level) while the underlying processes probably reflect everyday hour-to-hour fluctuations (micro level) as outlined above. In a study of 104 depressed patients by Bos et al. (2017; assessed ten times a day for five days) sadness was most sensitive to the other symptoms (highest instrength), whereas anhedonia had the most influence on other symptoms (outstrength). Daily level changes in positive mood, hopelessness, anger, and irritability most often activated other symptoms in anxious and depressed patients (Fisher et al., 2017), and thus not depressed mood, anhedonia, and worry, the putative cardinal symptoms (see Table 7.3). When studied on a weekly resolution, however, all symptoms of depression showed connections over time (either direct or indirectly), with anhedonia as the most central item (Bringmann et al., 2015). These examples illustrate that dynamic relationships differ across timescales (Dormann \& Griffin, 2015; Hamaker \& Wichers, 2017; Schiepek et al., 2016). Real-time changes in affect and rapidly cycling emotions (which require high-frequency assessments) must therefore be connected with changes in mood symptoms and negative cognitions (about the self and future), which mandate comparatively low-frequency measurements over weeks and months. Therapeutic processes, for example, cover both micro processes such as interactions within each session and more long-term sequential regularities that occur between consecutive sessions (see Chapter 4; Molenaar, 2010). Studies increasingly combine measurements across multiple "bursts" of intensive experience sampling over one year (Yang et al., 2018) which may help improve our understanding of mood in adolescence (Maciejewski et al., 2015).

A major application of dynamic system perspectives in contemporary mood research is the quest for generic early warning signals that may indicate upcoming transitions into a mood disorder episode, as such signals would enable for preventive strategies. Most attention goes to critical slowing down, enhanced symptom variability, and increasing autocorrelation as signals for transitions between such qualitatively different system states (Nelson et al., 2017; Wichers et al., 2015, 2016, 2018), but also frequency distributions, varying complexity, or other dynamic features are used (Molenaar, 2010; Schiepek et al., 2016). 
Table 7.3. Definitions of distress states according to the Diagnostic and Statistical manual of Mental Disorders (DSM-5)

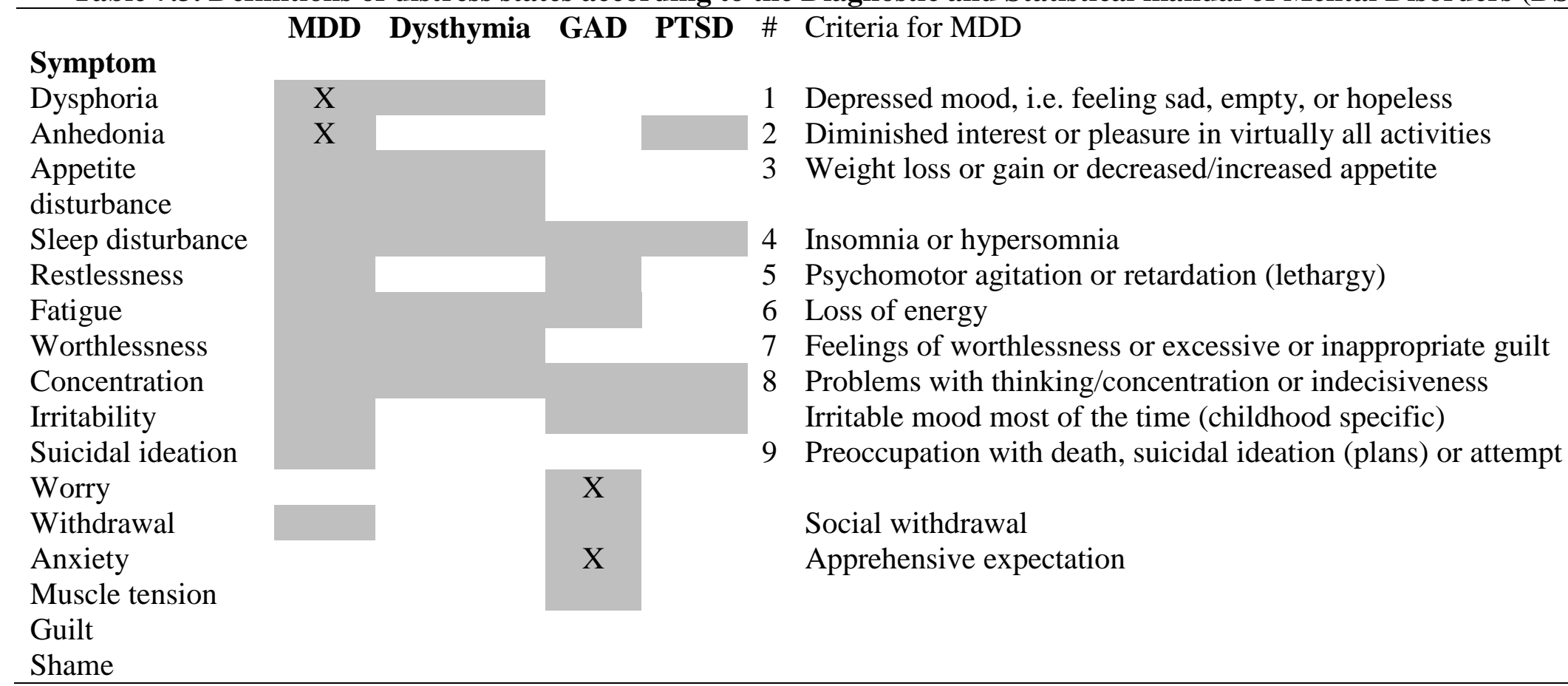

Note: $\mathrm{X}=$ core symptoms; MDD = major depressive disorder; GAD = generalized anxiety disorder; PTSD = post-traumatic stress disorder. Four major distress disorders can be identified in the DSM-5 (APA, 2013) on the basis of multiple experiences of which many are shared as indicated in gray (example derived from Lahey et al., 2017, table 1; but also see Kotov et al., 2017; Zahn-Waxler et al., 2000). Children can show several anxiety disorders, including separation anxiety, panic disorder, agoraphobia, specific phobia, social phobia, obsessive-compulsive disorder, generalized anxiety disorder (GAD), and post-traumatic stress disorder (PTSD). 
At the group-level there is some evidence for increases in autocorrelation (Van de Leemput et al., 2013) and higher system entropy before people experience a transition into a depressive state (Lanata et al., 2015). One individual-level study provided evidence for rising autocorrelations and variance before the onset of a depressed episode (Wichers et al., 2016). Studies of therapeutic contexts showed that increasing emotional fluctuations can indicate qualitative change (Lichtwarck-Aschoff et al., 2012; Schiepek, 2016).

Definite proof of generic early warning signals for the onset of anxiety or depression episodes requires researchers to monitor many individuals with high-frequency assessments over a long period in advance of the transition under study - and because such data has been collected with compliance rates of $80 \%$ and up (see Hoenders et al., 2012; Wichers et al., 2016, 2018; Schiepek et al., 2016), I expect studies that show whether the idea of warning signals has substance in the near future, which may result in the implementation of prevention strategies. At the group-level the timing of such discrete transitions in depressive symptom severity is inconsistent (De Zwart et al., 2018) which indicates substantial individual variability and sudden changes; This is illustrated in Figure 7.1, which shows the recovery trajectory of 267 participants over 140 weeks in terms of their depressive symptoms (a 50\% symptom reduction after 30 weeks) and demonstrates how uninformative group-level indicators can be for individual patterns. The idea of non-linear shifts in symptom severity combined with large individual variability favors knowledge on how symptoms evolve at the level of the individual in daily life to elucidate mechanisms, because the underlying causes are probably individualspecific (Fisher et al., 2018; Wichers et al., 2013; Yang et al., 2018). People who have been through an episode of psychosis or bipolar disorder often identified their individualized early warning signals for an upcoming future episode, which illustrates how dynamic system applications can lay hidden in routine care practices (see Chapter 4 for an elaboration).

Paradoxically, dynamic system perspectives also predict inherent limitations to the application of warning signals. Mood symptoms are connected via many feedback and multiplicative processes within individuals, which makes our development nonlinear and dynamic, as it depends on our current system state. As previously outlined with the weather metaphor, individual dynamics, emergent processes, thresholds of instability, and sudden transitions limit the predictability of developmental processes, and some futures shall therefore remain unknowable with precision, if only because tiny changes can compound to substantial outcome differences ("the butterfly effect," see Chapter 4; Boeing, 2016; Granic, 2005). Finally, the question remains as to whether mood disorder symptoms (Table 7.3) are defined at the right level of granularity to successfully identify the components of the system (as there may be hundreds of variables) while state transitions (if they exist) are likely to be governed by only a few (Borsboom, 2017; Van der Maas et al., 1992).

Promising future avenues to study anxious and depressed moods include the integration of complex dynamic processes across levels of resolution via simultaneous top-down and bottom-up approaches (Forbes et al., 2016; Witherington, 2007) and models that integrate within and between person estimates (Adolf et al., 2014; Ernst et al., 2019; Fisher et al., 2018). 
Figure 7.1. A group-level trajectory of depressive symptoms over 140 weeks (above) and the associated person-level trajectories (below) in 267 participants.
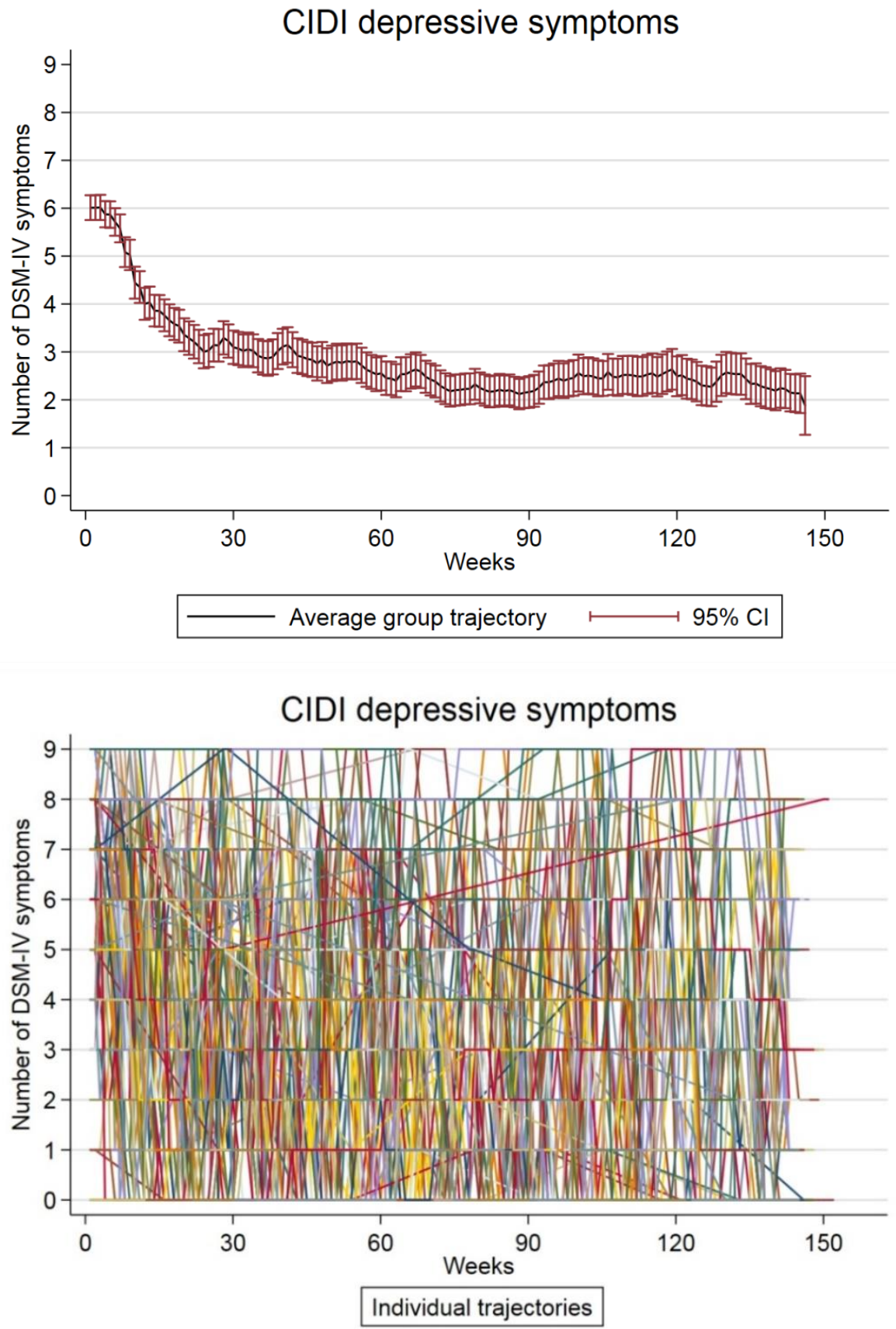

Note. The trajectory of depressive symptoms over 140 weeks as assessed with the composite international diagnostic interview (CIDI) based on the DSM-IV criteria, to study remission rates ( $\leq 5$ symptoms) and grouplevel changes over time. Source: Conradi et al. (2007). This figure was generously provided by Peter de Jonge and Elske Bos. 
Researchers increasingly estimate person-specific complex dynamic systems, which they subsequently aggregate into group-level clusters with more comparable dynamics and response synchronization processes (Beltz et al., 2016; Ernst et al., 2019; Yang et al., 2018), to inform etiological theories. Studies of mood dynamics often use regression-based methods to unravel autoregressive effects (how symptoms affect themselves) and cross-regressive effects (how symptoms affect each other) over time via VAR models using all lag-1 relations, which can handle unique direct effects, but not shared changes (i.e., shared variance is removed) or stable predictors (see Bulteel et al., 2016 and Molenaar, 2018, for a discussion of limitations, and Bringmann et al., 2013, for multilevel models, e.g. person-mean centering requires the assumption of stationarity).

Researchers also questioned the validity of using centrality indices to study mood symptom networks (Bringmann et al., 2018; Forbes et al., 2017; Hallquist et al., 2019), including betweenness and closeness centrality as measures of node importance (Bringmann et al., 2018), and struggled with statistical equivalent network and latent variable models despite their marked conceptual differences (Markman et al., 2018; Molenaar et al., 2007, 2010), which suggests that other and more advanced methodologies are required. Future studies might apply more advanced dynamic system techniques (examples in this book) and dynamic cluster models (Ernst et al., 2019) and more diverse and multimethod measures (e.g, observers, language analyses, interviews), as the almost exclusive usage of self-report measures of adolescents' anxiety and depression goes along with some threats to validity (Eisenberg et al., 2010), and should be interpreted with caution.

\section{Personality (macro level)}

Without pattern recognition our observations remain unfocused and random. Humans are highly variable and complex, but also show shared patterns in feelings, thoughts, and behaviors that persist over time and across situations. The "dynamic organization within the individual of those psychophysical traits that determine his unique adjustments to his environment" pertains to our personality (Allport, 1937). A large part of what makes each of us unique is our emotional life and idiographic history (Kuppens et al., 2009; McAdams, 2015). Most individual differences in these patterned characteristics can be summarized in terms of Five Factors or broad "trait families" (John et al., 2008), namely, Neuroticism, Extraversion, Conscientiousness, Agreeableness, and Openness to new experiences (the "Big Five"). Nowadays many theorists assume that personality "emerges out of the connectivity structure that exists between the various components of personality" (Cramer et al., 2012, p.414, also see Baumert et al., 2017; Constantini et al., 2019; Mõttus \& Allerhand, 2017; Ormel et al., 2017), a perspective similar to the constructivist perspectives on emotion and mood, but with different content and over longer time scales (see Table 7.1).

The neuroticism factor taps into the organization and functioning of negative emotion systems (APA, 2013, p.679; Ormel et al., 2013; Shackman et al., 2016), and refers to a dynamic 
macro-level structure of synchronized preferences, goals, values, concepts, motives, and narratives, which evolves in each of us while we develop along the lifespan (e.g., Back et al., 2011; Cramer et al., 2012; DeYoung, 2015; Fajkowska, 2015; Fleeson et al., 2015; Jayawickreme et al., 2019; Jeronimus, 2015; Lewis, 2000; McAdams, 2015; Mischel \& Shoda, 1995; Mõttus et al., 2018; Ormel et al., 2017; Tackett et al, 2012; Wrzus \& Roberts, 2017) ${ }^{1}$. Prominent members of the neuroticism family are the facet traits Anxiety and Depression (see Table 7.2 for definitions) and Vulnerability (or general susceptibility to stress), which capture the frequency and intensity with which adolescents experience the emotions anxiety and depression over time and in different situations (Costa \& McCrae, 2006), as well as current mood symptom levels (Kotov et al., 2010; Riese et al., 2015). The neuroticism trait family is a vulnerability for the later development of full-blown anxiety and depression disorders (Jeronimus et al., 2016). A key difference between mood episodes and the facet traits of Anxiety and Depression is that the former are deemed to indicate intra-individual deviations from our particular personal normality, whereas the latter refers to more permanent individual differences in personality dispositions (Jeronimus et al., 2013, 2016; Riese et al., 2015).

Neuroticism can be understood as an umbrella term or macro-level "attractor basin" for negative affect - the rather stable climatic "average weather" over adolescence - but this personality landscape changes over the lifespan, which can help explain why adolescence is marked by high intensity and variable emotion states of anxiety and depression. Most adolescents experience temporary decreases in conscientiousness (self-regulation) and agreeableness (warmth, friendliness and tact) and increase in neuroticism (Anxiety/Depression), a pattern that reverses from early adulthood onwards (see Roberts \& Wood, 2006 for a meta-analysis and Soto et al., 2011 for a cross-sectional study of 1 million participants). High neuroticism (or negative emotional reactivity and distress), and low conscientiousness (or poor effortful control and emotion regulation) and low extraversion (or low positive emotionality) underlie individual differences in sensitivity to reward and punishment and predict levels of anxiety and depression over adolescence (Watson et al., 2005; Rutter et al., 2011).

Emotion regulation refers to adolescents' abilities to regulate emotion dynamics back to their "normal" system state and the regulatory processes that are installed to keep their core affect in check ("attractor strength"; see Thompson, 1994; Kuppens et al., 2010), and dysfunctional patterns play a crucial role in the development and persistence of depression and anxiety (Jeronimus et al., 2016; Sendzik et al., 2017; Snyder et al., 2015). Most therapies therefore aim to re-establish cognitive control over emotions, via exposure, re-interpretation (of the way a situation is construed), or suppression (Gross, 2002), and clinicians increasingly focus on neuroticism as a target for therapy (Barlow et al., 2014; Roberts et al., 2017).

\footnotetext{
1 The various dynamic accounts of personality have a long history but recent accounts include CB5 theory (DeYoung, 2015), Mixed Model of Personality (Ormel et al., 2017), PERSOC (Back et al., 2011), and TESSERA (Wrzus \& Roberts, 2017), and Whole Trait Theory (Jayawickreme et al., 2019), among others.
} 
High neuroticism is associated with the "neurotic cascade" (Suls et al., 2005) which describes a set of processes that can help explain the recurrence of states of anxiety and depression: (a) heightened reactivity, exposure, and negative appraisals to signs of threat and negative emotion in the social world (Ormel et al., 2013; Shackman et al., 2016); (b) being exposed to more negative events (Jeronimus et al., 2013, 2014); (c) the tendency to appraise objectively neutral or positive events in negative terms (Laceulle et al., 2015; Shackman et al., 2016); (d) mood spill-over, whereby negative feelings in one area of life spill over into others (Jeronimus, 2015); and (e) excessive rumination, worries, and intolerance of uncertainty, which propel feelings of sadness and anxiety and decrease feelings of cheerfulness (Bringmann et al., 2013; Hong \& Cheung, 2015; Nolen-Hoeksema, 2000). High neuroticism and Anxiety/Depression are also marked by lower emotional granularity and clarity (Barrett, 2018; Carstensen et al., 2000; Luminet et al., 1999).

Next to the neurotic cascade, high neuroticism scores are also reflected in the way adolescents think and talk about themselves and construct their life narratives, as people vary in their emotional tone, themes, and complexity, which are fundamental aspects of our personality. High-neurotic people report more negatively toned biographical scenes, with more sadness and distress (but not more expressions of fear/anxiety), more negative inferences about themselves or others, more contamination sequences (i.e., good scenes that end poorly for them, which are associated with depression), less agency, and lower recall of specific positive memories (e.g., McAdams, 2015; Singer et al., 2013). Narrative identities subsume tasks, goals, projects, tactics, defences, values, and other developmental, motivational, and/or strategic concerns that contextualize individual lives in time, context, and social roles (McAdams, 2010, 2015). Such meaning-making processes are hallmark of the neuroticism system and treatment strategies (Hong \& Cheung, 2015; Roberts et al., 2017) may influence how adolescents experience reality (Laceulle et al., 2015).

\section{Dynamic perspectives}

Personality traits like neuroticism are often understood as dynamic equilibria (i.e., "attractor basin" or "set-point") around which micro- and meso-level elements fluctuate in response to life experiences (Fleeson \& Jajawickreme, 2015; Fleeson \& Law, 2015; Jeronimus et al., 2013; Ormel et al., 2017). Also the attractor landscape itself changes under influence of experiences, as neuroticism and anxiety/depression basins often become less deep after we take on new social roles such as worker or parent (Bleidorn et al., 2013; Roberts et al., 2006; Mund et al., 2018), but deepen in response to stressful life events (especially social stress and conflict) that can be characterized as unpredictable, uncontrollable, unexpected, undesirable, and non-normative from a life history perspective (Jeronimus, 2015). The components of the dynamic system deviate from their balanced configuration (in level or contingencies) until the old or a new homeostatic equilibrium is found.

Rapid increases in the facets anxiety and depression after stressful experiences (in terms of weeks and months) can be followed by slower external adaptation processes in our personal environment (in terms of years and decades) after which the affect landscape gravitates slowly 
back to the levels to which one was accustomed, due to substitution in resources, identity, habits, social support and social interaction - although these processes can also propel feedback loops that prevent regression towards the previous equilibrium, after which the person stabilizes in a new attractor (Jeronimus, 2015, p.260; Ormel et al., 2017). These hypotheses about developmental processes can be tested in detail when both the individual and the changing context are frequently and persistently sampled, but to the best of my knowledge, such high resolution data is currently unavailable.

People are thought to function in a relatively fixed region of a potentially large behavioral space, in balance with their environment, resulting in stable personality states (Cramer et al., 2012, p.416; Ormel et al., 2017) based on a Pareto-optimal allocation of one's energy budget, when no additional internal or external change can be made without increasing the costs somewhere else (e.g., Jeronimus, 2015, p.256). However, continuous small changes in our environment require adaptations to maintain this Pareto balance, and such fluctuations play out at the micro level. Future studies may unravel the relationship between differences in neuroticism and Anxiety or Depression facets and processes underlying dynamic fluctuations at the individual level. Whether the variation is over days or years, it is important to comprehend what it means for a person to vary from him or herself, and what it means for persons to vary from one another (Adolfs et al., 2014; Breiman, 2011; Fisher et al., 2018; Mroczek et al., 2003; Rose, 2016).

\section{Conclusion}

Anxiety and depression emerge from dynamic interactions between various affective, cognitive, and behavioral elements, which synchronize as emotions (micro), moods (macro), and personality traits (meso). In terms of emotions, the dynamic systems perspective supported an understanding of anxiety and depression as constructions of the world (rather than reactions to it), and suggests that changes in emotion dynamics can serve as warning signals for the development of a mood disorder, which could be highly valuable for prevention strategies. Although multiple studies support the existence of rapid transitions between normal and mood states, there is a dearth of literature that covers such transitions at the individual level.

Dynamic constructivist perspectives and evidence for connections between various anxiety and depression symptoms provided the field with a new explanation for the frequent co-occurrence of anxiety and depression states. Neuroticism was identified as a broad mesolevel attractor basin that is stabilized via "the neurotic cascade" and describes our inner climate, which makes some adolescents more prone to experience negative emotions including anxiety and depression, and more vulnerable to develop anxiety and depression disorders. The young age of onset for most anxiety and depression problems suggest that it would be cost-effective to influence these meso-level processes before adolescents let symptoms of anxiety and/or depression cascade into other spheres of functioning and the attractor landscape "stabilizes." 
Promising future avenues to improve our understanding of states of anxiety and depression include challenging studies that test various dynamic processes in single adolescents and examine changes therein over time. These studies ideally connect processes across multiple time scales, from real-time affective experiences, to the emergence of emotions and of emotion dysfunctions (which requires high-frequency sampling), and the development of symptoms of anxiety and depression and mood problems (which should be assessed in terms of weeks and months) and tendencies and personal narratives (in terms of years and decades). Only studies that capture all three levels (emotion, mood, personality) can illustrate how various emotion components synchronize and enable for the emergence of the macro and meso levels, which in turn influence and constrain the emotions and moods we experience - a circular causality that is the hallmark of the complex dynamic system that evolves within each of us. 


\section{References}

Adolf, J., Schuurman, N. K., Borkenau, P., Borsboom, D., \& Dolan, C. V. (2014).

Measurement invariance within and between individuals: a distinct problem in testing the equivalence of intra-and inter-individual model structures. Frontiers in psychology, 5 , 883. doi: 10.3389/fpsyg.2014.00883

Adolphs, R. (2003). Cognitive neuroscience of human social behaviour. Nature Reviews Neuroscience, 4(3), 165-178. doi:10.1038/nrn1056

Aldao, A., Nolen-Hoeksema, S., \& Schweizer, S. (2010). Emotion-regulation strategies across psychopathology: A meta-analytic review. Clinical Psychology Review, 30(2), 217-237.

Allport, G.W. (1937). Personality: A psychological interpretation. Oxford England: Holt.

American Psychiatric Association (2000). Diagnostic and statistical manual of mental disorders (4th ed., text rev.). Washington, DC: APA

American Psychiatric Association (2013). Diagnostic and statistical manual of mental disorders ( $5^{\text {th }}$ ed., or DSM-5). Washington, DC: APA

Anderson, D., \& Adolphs, R. (2014). A framework for studying emotions across species. Cell, 157(1), 187-200. doi:10.1016/j.cell.2014.03.003

Back, M.D., Baumert, A., Denissen, J.J.A., Hartung, F., Penke, L., Schmukle, S.C., Schönbrodt, F.D., Wrzus, C. (2011). PERSOC: A unified framework for understanding the dynamic interplay of personality and social relationships. European Journal of Personality, 25(2), 90-107. doi:10.1002/per.811

Bailen, N.H., Green, L.M., \& Thompson, R.J. (2019). Understanding Emotion in Adolescents: A Review of Emotional Frequency, Intensity, Instability, and Clarity. Emotion Review, 11(1). doi:10.1177/1754073918768878

Barlow, D. H., Sauer-Zavala, S., Carl, J. R., Bullis, J. R., \& Ellard, K. K. (2014). The nature, diagnosis, and treatment of neuroticism: Back to the future. Clinical Psychological Science, 2(3), 344-365. doi:10.1177/2167702613505532

Barrett, L.F. (2017). The theory of constructed emotion: An active inference account of interoception and categorization. Social cognitive and affective neuroscience, 12(1), 1-23. doi:10.1093/scan/nsw154

Barrett, L.F. (2018). How emotions are made: The secret life of the brain. Boston, MA: Houghton Mifflin Harcourt.

Baumert, A., Schmitt, M., Perugini, M., Johnson, W., Blum, G., Borkenau, P., ... \& Jayawickreme, E. (2017). Integrating personality structure, personality process, and personality development. European Journal of Personality, 31(5), 503-528. doi:10.1002/per.2115

Beedie, C., Terry, P., \& Lane, A. (2005). Distinctions between emotion and mood. Cognition and Emotion, 19(6), 847-878. doi:10.1080/02699930541000057

Beesdo, K., Knappe, S., Pine, D.S. (2009). Anxiety and anxiety disorders in children and adolescents: Developmental issues and implications for DSM-V. The Psychiatric Clinics of North America, 32(3), 483-524. doi:10.1016/j.psc.2009.06.002

Beltz, A.M., Wright, A.G., Sprague, B.N., \& Molenaar, P.C.M. (2016). Bridging the nomothetic and idiographic approaches to the analysis of clinical data. Assessment, 23(4), 447-458. doi:10.1177/1073191116648209

Bennik, E.C., Jeronimus, B.F., \& aan het Rot, M. (2019). The relation between empathy and depressive symptoms in a Dutch population sample. Journal of Affective Disorders, 242, 48-51. doi:10.1016/j.jad.2018.08.008

Birmaher, B. (2013). Bipolar disorder in children and adolescents. Child and Adolescent Mental Health, 18(3), 140-148. 
Bleidorn, W., Klimstra, T.A., Denissen, J.J., Rentfrow, P.J., Potter, J., Gosling, S.D. (2013). Personality maturation around the world: A cross-cultural examination of socialinvestment theory. Psychological Science, 24(12), 2530-2540. doi:10.1177/0956797613498396

Boeing, G. (2016). Visual analysis of nonlinear dynamical systems: chaos, fractals, selfsimilarity and the limits of prediction. Systems, 4(4), 37. doi: 10.3390/systems 4040037

Bolger, N., Stadler, G., \& Laurenceau, J. P. (2012). Power analysis for intensive longitudinal studies. In M. R. Mehl \& T. S. Conner (Eds.), Handbook of research methods for studying daily life (pp. 285-301). New York, NY, US: The Guilford Press.

Booij, S. H., Snippe, E., Jeronimus, B. F., Wichers, M., \& Wigman, J. T. (2018). Affective reactivity to daily life stress: relationship to positive psychotic and depressive symptoms in a general population sample. Journal of affective disorders, 225, 474-481. doi: 10.1016/j.jad.2017.08.051

Borsboom, D. (2008). Psychometric perspectives on diagnostic systems. Journal of clinical psychology, 64(9), 1089-1108. doi:10.1002/jclp.20503

Borsboom, D. (2017). A network theory of mental disorders. World Psychiatry, 16(1), 5-13. doi:10.1002/wps.20375

Bos, E.H., \& De Jonge, P. (2014). "Critical slowing down in depression" is a great idea that still needs empirical proof. Proceedings of the National Academy of Sciences, doi:10.1073/pnas.1323672111

Bos, E.H., de Jonge, P., Cox, R.F.H. (2018). Affective variability in depression: Revisiting the inertia-instability paradox. British Journal of Psychology, epub. doi:10.1111/bjop. 12372

Bos, F.M., Snippe, E., de Vos, S., Hartmann, J.A., Simons, C.J.P., Van der Krieke, L., De Jonge, P., Wichers, M. (2017). Can we jump from cross-sectional to dynamic interpretations of networks? Implications for the network perspective in psychiatry. Psychotherapy and Psychosomatics, 86(3), 175-177. doi:10.1159/000453583

Bos, E.H., Snippe, E., de Jonge, P., \& Jeronimus, B.F. (2016). Preserving subjective wellbeing in the face of psychopathology: buffering effects of personal strengths and resources. PloS one, 11(3), e0150867. doi:10.1371/journal.pone.0150867

Bos, E.H., Ten Have, M., van Dorsselaer, S., Jeronimus, B.F., de Graaf, R., \& de Jonge, P. (2018). Functioning before and after a major depressive episode: pre-existing vulnerability or scar? A prospective three-wave population-based study. Psychological medicine, 48(13), 2264-2272. doi:10.1017/S0033291717003798

Box, G.E.P., Jenkins, G.M., Reinsel, G.C., \& Ljung, G.M. (2015). Time Series Analysis: Forecasting and control. New York: John Wiley \& Sons.

Brackett, M.A., Rivers, S.E., Reyes, M.R., \& Salovey, P. (2012). Enhancing academic performance and social and emotional competence with the RULER feeling words curriculum. Learning and Individual Differences, 22(2), 218-224. doi:10.1016/j.lindif.2010.10.002

Brady, E.U., \& Kendall, P.C. (1992). Comorbidity of anxiety and depression in children and adolescents. Psychological Bulletin, 111(2), 244. doi:10.1037/0033-2909.111.2.244

Breiman, L. (2001). Statistical modeling: The two cultures (with comments and a rejoinder by the author). Statistical science, 16(3), 199-231. doi: 10.1214/ss/1009213726

Bringmann, L. F., Lemmens, L. H. J. M., Huibers, M. J. H., Borsboom, D., \& Tuerlinckx, F. (2015). Revealing the dynamic network structure of the Beck Depression InventoryII. Psychological medicine, 45(4), 747-757. doi:10.1017/S0033291714001809

Bringmann, L.F., Elmer, T., Epskamp, S., Krause, R.W., Schoch, D., Wichers, M., Wigman, J., Snippe, E. (2018). What do centrality measures measure in psychological networks? Researchgate preprint, november 2018. doi:10.13140/RG.2.2.25024.58884

Bringmann, L.F., Hamaker, E.L., Vigo, D.E., Aubert, A., Borsboom, D., Tuerlinckx, F. 
(2017). Changing dynamics: Time-varying autoregressive models using generalized additive modeling. Psychological Methods, 22, 409-425.

Bringmann, L.F., Vissers, N., Wichers, M., Geschwind, N., Kuppens, P., Peeters, F., Borsboom, D., Tuerlinckx, F. (2013). A network approach to psychopathology: New insights into clinical longitudinal data. Plos One, 8(4), e60188. doi:10.1371/journal.pone.0060188

Bulteel, K., Tuerlinckx, F., Brose, A., \& Ceulemans, E. (2016). Using raw VAR regression coefficients to build networks can be misleading. Multivariate behavioral research, 51(23), 330-344.

Burcusa, S.L., \& Iacono, W.G. (2007). Risk for recurrence in depression. Clinical Psychology Review, 27(8), 959-985. doi:10.1016/j.cpr.2007.02.005

Callahan, J., \& Sashin, J. I. (1990). Predictive models in psychoanalysis. Behavioral Science, 35(1), 60-76. doi:10.1002/bs.3830350107

Carstensen, L.L., Pasupathi, M., Mayr, U., \& Nesselroade, J. R. (2000). Emotional experience in everyday life across the adult life span. Journal of personality and social psychology, 79(4), 644.

Conradi, H. J., De Jonge, P., Kluiter, H., Smit, A., Jenner, J.A., Emmelkamp, P.M., \& Ormel, J. (2007). Enhanced treatment for depression in primary care: long-term outcomes of a psycho-educational prevention program alone and enriched with psychiatric consultation or cognitive behavioral therapy. Psychological medicine, 37(6), 849-862. doi:10.1017/S0033291706009809

Costantini, G., Richetin, J., Preti, E., Casini, E., Epskamp, S., \& Perugini, M. (2019). Stability and variability of personality networks. A tutorial on recent developments in network psychometrics. Personality and Individual Differences, 136, 68-78.

Costa, P.T., \& McCrae, R. (2006). Personality in adulthood: A five-factor theory perspective (2nd ed.). New York: Guilford Press.

Cowen, A. S., \& Keltner, D. (2017). Self-report captures 27 distinct categories of emotion bridged by continuous gradients. Proceedings of the National Academy of Sciences, 114(38), E7900-E7909. doi:10.1073/pnas.1702247114

Cramer, A.O., van Borkulo, C.D., Giltay, E.J., van der Maas, Han L.J., Kendler, K.S., Scheffer, M., Borsboom, D. (2016). Major depression as a complex dynamic system. PloS One, 11(12), e0167490. doi:10.1371/journal.pone.0167490

Cramer, A.O.J., Van der Sluis, S., Noordhof, A., Wichers, M., Geschwind, N., Aggen, S.H., Borsboom, D. (2012). Dimensions of normal personality as networks in search of equilibrium: You can't like parties if you don't like people. European Journal of Personality, 26(4), 414-431. doi:10.1002/per.1866

Cramer, A.O.J., Waldorp, L.J., Van der Maas, H.L.J., \& Borsboom, D. (2010). Comorbidity: A network perspective. Behavioral and Brain Sciences, 33(2-3), 137. doi:10.1017/S0140525X09991567

Damasio, A.R., Grabowski, T.J., Bechara, A., Damasio, H., Ponto, L.L., Parvizi, J., \& Hichwa, R.D. (2000). Subcortical and cortical brain activity during the feeling of selfgenerated emotions. Nature Neuroscience, 3(10), 1049-1056. doi:10.1038/79871

Darwin, C. (1872). The expression of the emotions in man and animals. London: John Murray.

Davis, S., Votruba-Drzal, E., \& Silk, J.S. (2015). Trajectories of internalizing symptoms from early childhood to adolescence: Associations with temperament and parenting. Social Development, 24(3), 501-520.

Demiralp, E., Thompson, R.J., Mata, J., Jaeggi, S.M., Buschkuehl, M., Barrett, L.F., Ellsworth, P.C., Demiralp, M., Hernandez-Garcia, L., Deldin, P.J., Gotlib, I.H. (2012). 
Feeling blue or turquoise? Emotional differentiation in major depressive disorder. Psychological science, 23(11), 1410-1416.

De Waal (2019). Mama's last hug. Animal emotions and what they tell us about ourselves. New York: Norton.

De Zwart, P., Jeronimus, B.F., De Jonge, P. (2018). Empirical evidence for definitions of episode, remission, recovery, relapse and recurrence in depression: A systematic review. Epidemiology and Psychiatric Sciences, 1-19. doi:10.1017/S2045796018000227

DeYoung, C.G. (2015). Cybernetic big five theory. Journal of research in personality, 56, 3358. doi:10.1016/j.jrp.2014.07.004

Dormann, C., \& Griffin, M.A. (2015). Optimal time lags in panel studies. Psychological Methods, 20(4), 489.

Eisenberg, N., Spinrad, T.L., \& Eggum, N.D. (2010). Emotion related self-regulation and its relation to children's maladjustment. Annual Review of Clinical Psychology, 6, 495-525.

Ekman, P. (2008). Gegrepen door emoties. Amsterdam: Uitgeverij Nieuwezijds.

Erbas, Y., Ceulemans, E., Lee Pe, M., Koval, P., Kuppens, P. (2014). Negative emotion differentiation: Its personality and well-being correlates and a comparison of different assessment methods. Cognition and Emotion, 28(7), 1196-1213.

Ernst, A.F., Albers, C.J., Jeronimus, B.F., Timmerman, M.E. (2019). Inter-individual differences in multivariate time series: Dynamic adaptive cluster modelling based on finite mixtures of vector-autoregressive processes.

Ernst, A.F., Timmerman, M.E., Jeronimus, B.F., Albers, C.J. (2019). Insight into individual differences in emotion dynamics with clustering. Assessment, first online.

Fajkowska, M. (2015). The complex-system approach to personality: Main theoretical assumptions. Journal of Research in Personality, 56, 15-32. doi:10.1016/j.jrp.2014.09.003

Fisher, A. J., Reeves, J. W., Lawyer, G., Medaglia, J. D., \& Rubel, J. A. (2017). Exploring the idiographic dynamics of mood and anxiety via network analysis. Journal of abnormal psychology, 126(8), 1044. doi:10.1037/abn0000311

Fisher, A.J., Medaglia, J.D., \& Jeronimus, B.F. (2018). Lack of group-to-individual generalizability is a threat to human subjects research. Proceedings of the National Academy of Sciences, 115(27), 6105-5115. doi:10.1073/pnas.1711978115

Fleeson, W., \& Jayawickreme, E. (2015). Whole trait theory. Journal of Research in Personality, 56, 82-92. doi:10.1016/j.jrp.2014.10.009

Fleeson, W., \& Law, M. K. (2015). Trait enactments as density distributions: The role of actors, situations, and observers in explaining stability and variability. Journal of Personality and Social Psychology, 109(6), 1090. doi: 10.1037/a0039517

Fogel, A., Nwokah, E., Dedo, J.Y., Messinger, D., Dickson, K.L., Matusov, E., \& Holt, S.A. (1992). Social process theory of emotion: A dynamic systems approach. Social Development, 1(2), 122-142.

Forbes, M.K., Tackett, J.L., Markon, K.E., Krueger, R.F. (2016). Beyond comorbidity: Toward a dimensional and hierarchical approach to understanding psychopathology across the life span. Development and Psychopathology, 28(4), 971-986. doi:10.1017/S0954579416000651

Forbes, M.K., Wright, A.G., Markon, K.E., Krueger, R.F. (2017). Evidence that psychopathology symptom networks have limited replicability. Journal of Abnormal Psychology, 126(7), 969.

Fried, E.I., \& Nesse, R.M. (2015). Depression sum-scores don't add up: Why analyzing specific depression symptoms is essential. BMC Medicine, 13, 72.

doi:10.1186/s12916-015-0325-4 
Fried, E. I., van Borkulo, C. D., Cramer, A. O., Boschloo, L., Schoevers, R. A., \& Borsboom, D. (2017). Mental disorders as networks of problems: a review of recent insights. Social Psychiatry and Psychiatric Epidemiology, 52(1), 1-10. doi: 10.1007/s00127-016-1319-z

Gohm, C.L., \& Clore, G.L. (2000). Individual differences in emotional experience: Mapping available scales to processes. Personality and Social Psychology Bulletin, 26(6), 679697.

Gotlib, I.H., \& Joormann, J. (2010). Cognition and depression: current status and future directions. Annual review of clinical psychology, 6, 285-312. doi:10.1146/annurev.clinpsy.121208.131305

Granic, I. (2005). Timing is everything: Developmental psychopathology from a dynamic systems perspective. Developmental Review, 25(3), 386-407. doi:10.1016/j.dr.2005.10.005

Gross, J.J. (2002). Emotion regulation: Affective, cognitive, and social consequences. Psychophysiology, 39(3), 281-291. doi:10.1017.S0048577201393198

Hallquist, M., Wright, A. G., \& Molenaar, P.C. (2019). Problems with centrality measures in psychopathology symptom networks: Why network psychometrics cannot escape psychometric theory. doi:10.31234/osf.io/pg4mf

Hamaker, E.L., \& Grasman, R.P.P.P. (2012). Regime switching state-space models applied to psychological processes: Handling missing data and making inferences.

Psychometrika, 77(2), 400-422.

Hamaker, E.L., \& Wichers, M. (2017). No time like the present: Discovering the hidden dynamics in intensive longitudinal data. Current Directions in Psychological Science, 26(1), 10-15. doi:10.1177/0963721416666518

Haslbeck, J.M.B., \& Fried, E.I. (2017). How predictable are symptoms in psychopathological networks? A reanalysis of 18 published datasets. Psychological medicine, 47(16), 2767-2776. doi:10.1017/S0033291717001258

Hayes, A.M., Laurenceau, J.P., Feldman, G., Strauss, J.L., \& Cardaciotto, L. (2007). Change is not always linear: The study of nonlinear and discontinuous patterns of change in psychotherapy. Clinical Psychology Review, 27(6), 715-723. doi:10.1016/j.cpr.2007.01.008

Heeren, A., Bernstein, E.E., McNally, R.J. (2018). Deconstructing trait anxiety: A network perspective. Anxiety, Stress, \& Coping, 31(3), 262-276. doi:10.1080/10615806.2018.1439263

Hoenders, H.R., Bos, E.H., De Jong, J.T., \& De Jonge, P. (2012). Temporal dynamics of symptom and treatment variables in a lifestyle-oriented approach to anxiety disorder: A single-subject time-series analysis. Psychotherapy and psychosomatics, 81(4), 253-255.

Hollenstein, T. (2015). This time, it's real: Affective flexibility, time scales, feedback loops, and the regulation of emotion. Emotion Review, 7(4), 308-315.

Hong, R.Y., \& Cheung, M.W.L. (2015). The structure of cognitive vulnerabilities to depression and anxiety: Evidence for a common core etiologic process based on a metaanalytic review. Clinical Psychological Science, 3(6), 892-912.

Horwitz, A.V., \& Wakefield, J.C. (2007). The loss of sadness: How psychiatry transformed normal sorrow into depressive disorder. New York: Oxford University Press.

Hosenfeld, B., Bos, E.H., Wardenaar, K.J., Conradi, H.J., Maas, H.L., Visser, I., De Jonge, P. (2015). Major depressive disorder as a nonlinear dynamic system: Bimodality in the frequency distribution of depressive symptoms over time. BMC Psychiatry, 15(1), 222. doi:10.1186/s12888-015-0596-5

Houben, M., Van den Noortgate, W., Kuppens, P. (2015). The relation between short-term emotion dynamics and psychological well-being: A meta-analysis. Psychological Bulletin, 141(4), 901. doi:10.1037/a0038822 
Hovenkamp-Hermelink, J. H., Jeronimus, B. F., Spinhoven, P., Penninx, B. W., Schoevers, R. A., \& Riese, H. (2019). Differential associations of locus of control with anxiety, depression and life-events: A five-wave, nine-year study to test stability and change. Journal of affective disorders, 253, 26-34. doi: 10.1016/j.jad.2019.04.005

Isen, A.M. (1990). The influence of positive and negative affect on cognitive organization:

Some implications for development. In Stein, N.L., Leventhal, B., \& Trabasso, T. (Eds.). Psychological and Biological Approaches to Emotion (pp. 75-94). Hillsdale, NJ: Lawrence Erlbaum Associates.

James, W. (1890). The Principles of Psychology, Vol. 2. New York: Cosimo Classics. Jayawickreme, E., Zachry, C. E., \& Fleeson, W. (2019). Whole trait theory: An integrative approach to examining personality structure and process. Personality and Individual Differences, 136, 2-11. doi:10.1016/j.paid.2018.06.045

Jeronimus, B.F., Laceulle, O.M. (2017). Frustration. In V. Zeigler-Hill, \& T. K. Shackelford (Eds.), Encyclopedia of personality and individual differences. New York: Springer.

Jeronimus, B.F., Riese, H., Oldehinkel, A.J., Ormel, J. (2017). Why does frustration predict psychopathology? Multiple prospective pathways over adolescence: A TRAILS study. European Journal of Personality, 31(1), 85-103. doi: 10.1002/per.2086

Jeronimus, B.F. (2015). Environmental influences on neuroticism: A story about emotional (in)stability. Groningen, the Netherlands: University of Groningen. doi: 10.13140/2.1.3452.2407

Jeronimus, B.F., Kotov, R., Riese, H., Ormel, J. (2016). Neuroticism's prospective association with mental disorders: A meta-analysis on 59 longitudinal/prospective studies with 443 313 participants. Psychological Medicine, 46(14), 2883-2906. doi:10.1017/S0033291716001653

Jeronimus, B.F., Riese, H., Sanderman, R., Ormel, J. (2014). Mutual reinforcement between neuroticism and life experiences: A five-wave, 16-year study to test reciprocal causation. Journal of Personality and Social Psychology, 107(4), 751.

Jeronimus, B.F., Ormel, J., Aleman, A., Penninx, B.W., Riese, H. (2013). Negative and positive life events are associated with small but lasting change in neuroticism. Psychological medicine, 43(11), 2403-2415. doi: $10.1017 / \mathrm{S} 0033291713000159$

Jeronimus, B.F., Riese, H. (2016). If it ain't broke, don't fix it: Depressive traits are part and parcel of neuroticism revisited. Psychoneuroendocrinology, 65, 165. doi:10.1016/j.psyneuen.2015.12.005.

Jeronimus, B. F., Snippe, E., Emerencia, A. C., de Jonge, P., \& Bos, E. H. (2018). Acute stress responses after indirect exposure to the MH 17 airplane crash. British Journal of Psychology. doi: 10.1111/bjop.12358

John, O.P., Robins, R., \& Pervin, L.A. (2008). Handbook of personality: Theory and research (3rd ed.). New York: Guilford.

Judd, L.L., Akiskal, H.S., Maser, J.D., Zeller, P.J., Endicott, J., Coryell, W., Paulus, M.P., Kunovac, J.L., Leon, A.C., Mueller, T.I., Rice, J.A., Keller, M.B. (1998). A Prospective 12-Year Study of Subsyndromal and Syndromal Depressive Symptoms in Unipolar Major Depressive Disorders. Archives of General Psychiatry, 55(8), 694-700. doi:10.1001/archpsyc.55.8.694

Kahneman, D., \& Egan, P. (2011). Thinking, fast and slow (Vol. 1). New York: Farrar, Straus and Giroux.

Kashdan, T.B., Farmer, A.S. (2014). Differentiating emotions across contexts: Comparing adults with and without social anxiety disorder using random, social interaction, and daily experience sampling. Emotion, 14(3), 629. 
Kashdan, T.B., Barrett, L.F., McKnight, P.E. (2015). Unpacking emotion differentiation: Transforming unpleasant experience by perceiving distinctions in negativity. Current Directions in Psychological Science, 24(1), 10-16.

Kendler, K.S. (2012). The dappled nature of causes of psychiatric illness: Replacing the organic-functional/hardware-software dichotomy with empirically based pluralism. Molecular Psychiatry, 17(4), 377-388. doi:10.1038/mp.2011.182

Kendler K.S., Parnas J. (eds). (2015) Philosophical Issues in Psychiatry III: The Nature and Sources of Historical Change, Oxford: Oxford University Press.

Kendler, K.S., Zachar, P., \& Craver, C. (2011). What kinds of things are psychiatric disorders? Psychological Medicine, 41(6), 1143-1150. doi:10.1017/S0033291710001844

Kessler, R.C., Wang, P.S. (2009). The epidemiology of depression. In Gotlib, I.H., Hammen, C.L. (Eds.), Handbook of Depression (2 ${ }^{\text {nd }}$ ed., pp. 5-22). New York: Guilford.

Kotov, R., Gamez, W., Schmidt, F., \& Watson, D. (2010). Linking "big” personality traits to anxiety, depressive, and substance use disorders: a meta-analysis. Psychological bulletin, 136(5), 768. doi:10.1037/a0020327

Kotov, R., Krueger, R. F., Watson, D., Achenbach, T. M., Althoff, R. R., Bagby, R. M., ... \& Eaton, N. R. (2017). The Hierarchical Taxonomy of Psychopathology (HiTOP): a dimensional alternative to traditional nosologies. Journal of abnormal psychology, 126(4), 454. doi:10.1037/abn0000258

Koval, P., Pe, M.L., Meers, K., Kuppens, P. (2013). Affect dynamics in relation to depressive symptoms: Variable, unstable, or inert? Emotion, 13, 1132-1141.

Krone, T., Albers, C.J., Kuppens, P., \& Timmerman, M. (2018). A multivariate statistical model for emotion dynamics. Emotion, 18(5), 739-754. doi:10.1037/emo0000384

Kunnen, E.S., De Ruiter, N.M.P., Jeronimus, B.F., van der Gaag, M.A. (2019). Psychosocial Development in Adolescence: Insights from the Dynamic Systems Approach. New York: Routledge Psychology.

Kuppens, P., Stouten, J., \& Mesquita, B. (2009). Individual differences in emotion components and dynamics: Introduction to the special issue. Cognition and Emotion, 23(7), 1249-1258. doi:10.1080/02699930902985605

Kuppens, P., Oravecz, Z., Tuerlinckx, F. (2010). Feelings change: Accounting for individual differences in the temporal dynamics of affect. Journal of personality and social psychology, 99(6), 1042. doi:10.1037/a0020962

Kuppens, P., Sheeber, L.B., Yap, M.B.H., Whittle, S., Simmons, J.G., Allen, N.B. (2012). Emotional inertia prospectively predicts the onset of depressive disorder in adolescence. Emotion, 12(2), 283-289. doi:10.1037/a0025046

Kuppens, P., Verduyn, P. (2017). Emotion dynamics. Current Opinion in Psychology, 17, 2226. doi: 10.1016/j.copsyc.2017.06.004

Laceulle, O.M., Jeronimus, B.F., Van Aken, M.A.G., Ormel, J. (2015). Why not everybody gets their fair share of stress: Adolescent's perceived relationship affection mediates associations between temperament and subsequent stressful social events. European Journal of Personality, 29(2), 125-37. doi:10.1002/per.1989

Lahey, B. B., Krueger, R. F., Rathouz, P. J., Waldman, I. D., \& Zald, D. H. (2017). A hierarchical causal taxonomy of psychopathology across the life span. Psychological bulletin, 143(2), 142. doi:10.1037/bul0000069

Lanata, A., Valenza, G., Nardelli, M., Gentili, C., Scilingo, E.P. (2015). Complexity index from a personalized wearable monitoring system for assessing remission in mental health. IEEE Journal of Biomedical and Health Informatics, 19(1), 132-139. doi:10.1109/JBHI.2014.2360711

Larsen, R. J. (1987). The stability of mood variability: A spectral analytic approach to daily mood assessments. Journal of Personality and Social Psychology, 52(6), 1195-1204. 
doi:10.1037/0022-3514.52.6.1195

LeDoux, J.E. (2000). Emotion circuits in the brain. Annual Review of Neuroscience, 23(1), 155-184. doi:10.1146/annurev.neuro.23.1.155

Lewis, M.D. (2000). Emotional self-organization at three time scales. (pp. 37-69). New York, NY, US: Cambridge University Press. doi:10.1017/CBO9780511527883.004

Lewis, M.D. (2005). Bridging emotion theory and neurobiology through dynamic modeling. Behavioral and Brain Sciences, 28, 169 -194. doi: 10.1017/S0140525X0500004X

Lichtwarck-Aschoff, A., Hasselman, F., Cox, R., Pepler, D., \& Granic, I. (2012). A characteristic destabilization profile in parent-child interactions associated with treatment efficacy for aggressive children. Nonlinear Dynamics-Psychology and Life Sciences, 16(3), 353.

Lieberman, M. D., Inagaki, T. K., Tabibnia, G., \& Crockett, M. J. (2011). Subjective responses to emotional stimuli during labeling, reappraisal, and distraction. Emotion, 11(3), 468-480. doi:10.1037/a0023503

Liljenström, H., Svedin, U. (2005). System features, dynamics, and resilience. In: Micro, meso, macro: Addressing complex systems couplings (pp. 1-18). London: World Scientific.

Luminet, O., Bagby, R.M., Wagner, H., Taylor, G.J., Parker, J.D. (1999). Relation between alexithymia and the five-factor model of personality: A facet-level analysis. Journal of personality assessment, 73(3), 345-358.

Maas, C.J., \& Hox, J.J. (2005). Sufficient sample sizes for multilevel modeling. Methodology, 1(3), 86-92. doi:10.1027/1614-2241.1.3.86.

Maciejewski, D.F., van Lier, P.A., Branje, S.J., Meeus, W.H., \& Koot, H.M. (2015). A 5year longitudinal study on mood variability across adolescence using daily diaries. Child development, 86(6), 1908-1921. doi:10.1111/cdev.12420

Marsman, M., Borsboom, D., Kruis, J., Epskamp, S., Bork, R. van, Waldorp, L.J., ... Maris, G. (2018). An Introduction to Network Psychometrics: Relating Ising Network Models to Item Response Theory Models. Multivariate Behavioral Research, 53(1), 15-35. doi:10.1080/00273171.2017.1379379

Mathews, B.L., Koehn, A.J., Abtahi, M.M., Kerns, K.A. (2016). Emotional competence and anxiety in childhood and adolescence: A meta-analytic review. Clinical child and family psychology review, 19(2), 162-184. doi: 10.1007/s10567-016-0204-3

McAdams, D.P. (2015). The art and science of personality development. New York: The Guilford Press.

McAdams, D. P., \& Olson, B. D. (2010). Personality development: Continuity and change over the life course. Annual review of psychology, 61, 517-542.

McNally, R. J. (2016). Can network analysis transform psychopathology?. Behaviour Research and Therapy, 86, 95-104. doi:10.1016/j.brat.2016.06.006

Medaglia, J.D., Jeronimus, B.F., Fisher, A.F.J. (2019). Conditional equivalence and imperatives for person-level science. Proceedings of the National Academy of Sciences, 116(14), 6542-6543. doi: 10.1073/pnas.1820221116

Merikangas, K.R., He, J.P., Burstein, M., Swanson, S.A., Avenevoli, S., Cui, L., Benjet, C., Georgiades, K., Swendsen, J. (2010). Lifetime prevalence of mental disorders in US adolescents: results from the National Comorbidity Survey Replication-Adolescent Supplement (NCS-A). Journal of the American Academy of Child \& Adolescent Psychiatry, 49(10), 980-989. doi:10.1016/j.jaac.2010.05.017

Mischel, W., \& Shoda, Y. (1995). A cognitive-affective system theory of personality: Reconceptualizing situations, dispositions, dynamics, and invariance in personality structure. Psychological Review, 102(2), 246-268. doi:10.1037/0033-295X.102.2.246 
Molenaar, P.C.M. (2010). Note on optimization of individual psychotherapeutic processes. Journal of Mathematical Psychology, 54(1), 208-213.

Molenaar, P. C. M. (2010). Latent variable models are network models. Behavioral and Brain Sciences, 33(2-3), 166-166. doi:10.1017/S0140525X10000798

Molenaar, P.C.M., van Rijn, P., \& Hamaker, E. (2007). A new class of SEM model equivalences and its implications. In S. M. Boker \& M. J. Wenger (Eds.), Data analytic techniques for dynamical systems (pp. 189-211). Erlbaum.

Molenaar, P.C.M. (2018). Granger Causality Testing with Intensive Longitudinal Data. Prevention Science, 1-10. doi:10.1007/s11121-018-0919-0

Morgan, J.K., Lee, G.E., Wright, A.G.C., Gilchrist, D.E., Forbes, E.E., McMakin, D.L., Dahl, R.E., Ladouceur, C.D., Ryan, N.D., \& Silk, J.S. (2017). Altered positive affect in clinically anxious youth: The role of social context and anxiety subtype. Journal of Abnormal Child Psychology, 45, 1461-1472. doi:10.1007/s10802-016-0256-3.

Mõttus, R., Briley, D.A., Zheng, A., Mann, F.D., Engelhardt, L.E., Tackett, J.L., Harden, K.P, Tucker-Drob, E.M. (2018). Kids becoming less alike: A behavioral genetic analysis of developmental increases in personality variance from childhood to adolescence. Journal of social and personality psychology. doi:10.1037/pspp0000194

Mõttus, R., \& Allerhand, M. (2017). Why do traits come together? The underlying trait and network approaches. SAGE handbook of personality and individual differences, 1, 1-22.

Mroczek, D. K., \& Spiro III, A. (2003). Modeling intraindividual change in personality traits: Findings from the Normative Aging Study. The Journals of Gerontology Series B:

Psychological Sciences and Social Sciences, 58(3), P153-P165. doi:10.1093/geronb/58.3.P153

Mund, M., Jeronimus, B.F., Neyer, F.J. (2018). Personality and social relationships: As thick as thieves. In: Johansen, C. (Ed.), Your personality makes you ill: Scientific proof or wishful thinking? (pp. 153-183). Amsterdam: Elsevier. doi:10.1016/B978-0-12-805300-3.00009-8

Myin-Germeys, I., Oorschot, M., Collip, D., Lataster, J., Delespaul, P., Van Os, J. (2009). Experience sampling research in psychopathology: Opening the black box of daily life. Psychological Medicine, 39(9), 1533-1547. doi:10.1017/S0033291708004947

Nelson, B., McGorry, P.D., Wichers, M., Wigman, J.W., Hartmann, J.A. (2017). Moving from static to dynamic models of the onset of mental disorder: A review. JAMA Psychiatry, 74(5), 528-534. doi:10.1001/jamapsychiatry.2017.0001

Neumann, A., Van Lier, P.A., Frijns, T., Meeus, W., \& Koot, H.M. (2011). Emotional dynamics in the development of early adolescent psychopathology: A one-year longitudinal study. Journal of Abnormal Child Psychology, 39(5), 657-669.

Nolen-Hoeksema, S. (2000). The role of rumination in depressive disorders and mixed anxiety/depressive symptoms. Journal of Abnormal Psychology, 109(3), 504.

Nook, E.C., Sasse, S.F., Lambert, H.K., McLaughlin, K.A., Somerville, L.H. (2018). The nonlinear development of emotion differentiation: Granular emotional experience is low in adolescence. Psychological Science, 29(8), 1346-1357. doi:0956797618773357.

Ochsner, K.N., Silvers, J.A., \& Buhle, J.T. (2012). Functional imaging studies of emotion regulation: A synthetic review and evolving model of the cognitive control of emotion. Year in Cognitive Neuroscience, 1251, E1-E24. doi:10.1111/j.1749-6632.2012.06751.x

Opsahl, T., Agneessens, F., \& Skvoretz, J. (2010). Node centrality in weighted networks: Generalizing degree and shortest paths. Social networks, 32(3), 245-251. doi:10.1016/j.socnet.2010.03.006

Ormel, J., Jeronimus, B.F., Kotov, R., Riese, H., Bos, E.E., Hankin, B., \& Rosmalen, J.G.M. (2013). Neuroticism and common mental disorders: Meaning and utility of a complex relationship. Clinical Psychology Review, 33(5), 686-697. 
Ormel, J., VonKorff, M., Jeronimus, B.F., Riese, H. (2017). Set-point theory and personality development: Reconciliation of a paradox. In: Specht, J. (Ed.), Personality development across the lifespan (pp. 117-138). London: Academic Press.

Ortony, A., Turner, T.J. (1990). What's basic about basic emotions? Psychological Review, 97(3), 315-331. doi: 10.1037/0033-295X.97.3.315

Palser, E.R., Palmer, C.E., Galvez-Pol, A., Hannah, R., Fotopoulou, A., Kilner, J.M. (2018). Alexithymia mediates the relationship between interoceptive sensibility and anxiety. Plos One, 13(9): e0203212. doi: 10.1371/journal.pone.0203212

Panksepp, J., Biven, L. (2012). The archaeology of mind: Neuroevolutionary origins of human emotions. New York: Norton \& Company.

Plutchik, R. (2001). The nature of emotions: Human emotions have deep evolutionary roots, a fact that may explain their complexity and provide tools for clinical practice. American Scientist, 89(4), 344-350. doi:10.1511/2001.28.739

Posner, J., Russell, J.A., \& Peterson, B.S. (2005). The circumplex model of affect: An integrative approach to affective neuroscience, cognitive development, and psychopathology. Development and Psychopathology, 17(03), 715-734. doi:10.1017/S0954579405050340

Reitsema, A.M., Jeronimus, B.F., van Dijk, M., de Jonge, P. (2019). Emotion dynamics in children and adolescents: A systematic and multi-level meta-analytic and descriptive review. Preprint.

Revelle, W., \& Condon, D.M. (2017). Climate:Weather:Traits:States. European Journal of Personality, 31(5), 564-65.

Revonsuo, A. (2000). The reinterpretation of dreams: An evolutionary hypothesis of the function of dreaming. Behavioral and Brain Sciences, 23(6), 877-901.

Riese, H., Snieder, H., Jeronimus, B. F., Korhonen, T., Rose, R. J., Kaprio, J., \& Ormel, J. (2014). Timing of stressful life events affects stability and change of neuroticism. European Journal of Personality, 28(2), 193-200. doi:10.1002/per.1929

Riese, H., Ormel, J., Aleman, A., Servaas, M.N., \& Jeronimus, B.F. (2015). Don't throw the baby out with the bathwater: Depressive traits are part and parcel of neuroticism. NeuroImage, doi:10.1016/j.neuroimage.2015.11.012

Roberts, B.W., Wood, D. (2006). Personality Development in the Context of the NeoSocioanalytic Model of Personality. In: Mroczek, D.K., Little, T.D. (Eds.), Handbook of personality development (pp. 11-39). Mahwah, NJ, US: Lawrence Erlbaum Associates Publishers.

Roberts, B.W., Luo, J., Briley, D.A., Chow, P.I., Su, R., Hill, P.L. (2017). A systematic review of personality trait change through intervention. Psychological Bulletin, 143(2), 117. doi:10.1037/bul0000088

Rose, T. (2016). The end of average: How to succeed in a world that values sameness. Penguin. UK.

Roseman, I. J., Wiest, C., \& Swartz, T. S. (1994). Phenomenology, behaviors, and goals differentiate discrete emotions. Journal of personality and social psychology, 67(2), 206. doi:10.1037/0022-3514.67.2.206

Rottenberg, J., Devendorf, A.R., Kashdan, T.B., Disabato, D.J. (2018). The curious neglect of high functioning after psychopathology: The case of depression. Perspectives on psychological science, 13(5), 549-566. doi:10.1177/1745691618769868

Russell, J. A. (1980). A circumplex model of affect. Journal of personality and social psychology, 39(6), 1161. doi:10.1037/h0077714

Russell, J.A. (1990). In defense of a prototype approach to emotion concepts. Journal of Personality and Social Psychology, 60, 37-47. 
Russell, J.A. (2003). Core affect and the psychological construction of emotion. Psychological Review, 110(1), 145-172. doi:10.1037/0033-295X.110.1.145

Russell, J.A. (2017). Mixed emotions viewed from the psychological constructionist perspective. Emotion Review, 9(2), 111-117. doi:10.1177/1754073916639658

Rutter, M., Bishop, D.V.M., Pine, D.S., Scott, S., Stevenson, J., Taylor, E., Thapar, A. (Eds.). (2011). Rutter's child and adolescent psychiatry (5.3rd ed.). Malden, Massachusetts, USA: Wiley-Blackwell.

Salzman, C.D., Fusi, S. (2010). Emotion, cognition, and mental state representation in amygdala and prefrontal cortex. Annual Review of Neuroscience, 33(1), 173-202. doi:10.1146/annurev.neuro.051508.135256

Scheffer, M., Carpenter, S.R., Lenton, T.M., Bascompte, J., Brock, W., Dakos, V., Van de Koppel, J., Van de Leemput, I.A., Levin, S.A., Van Nes, E.H., Pascual, M. (2012). Anticipating critical transitions. Science, 338(6105), 344-348. doi:10.1126/science. 1225244

Scherer, K.R. (2009). Emotions are emergent processes: They require a dynamic computational architecture. Philosophical Transactions of the Royal Society B: Biological Sciences, 364(1535), 3459-3474. doi:10.1098/rstb.2009.0141

Schiepek, G., Aichhorn, W., Gruber, M., Strunk, G., Bachler, E., \& Aas, B. (2016). Real-time monitoring of psychotherapeutic processes: concept and compliance. Frontiers in psychology, 7, 604. doi: 10.3389/fpsyg.2016.00604

Schooler, J.W., Smallwood, J., Christoff, K., Handy, T.C., Reichle, E.D., Sayette, M.A. (2011). Meta-awareness, perceptual decoupling and the wandering mind. Trends in cognitive sciences, 15(7), 319-326.

Schwarz, N. (2010). Feelings-as-information theory. In: Van Lange, P., Kruglanski, A., Higgins, E.T. (Eds.), Handbook of theories of social psychology (pp. 289-308). Michigan. Sage.

Searle, J. R. (1984). Minds, brains and science. Cambridge, MA: Harvard University Press.

Sendzik, L., Schäfer, J.Ö., Samson, A.C., Naumann, E., Tuschen-Caffier, B. (2017). Emotional awareness in depressive and anxiety symptoms in youth: A meta-analytic review. Journal of youth and adolescence, 46(4), 687-700. doi:10.1007/s10964-0170629-0

Shackman, A.J., Tromp, D.P.M., Stockbridge, M.D., Kaplan, C.M., Tillman, R.M., \& Fox, A.S. (2016). Dispositional negativity: An integrative psychological and neurobiological perspective. Psychological Bulletin, 142(12), 1275-1314. doi:10.1037/bul0000073

Shaver, P., Schwartz, J., Kirson, D., \& O'connor, C. (1987). Emotion knowledge: further exploration of a prototype approach. Journal of personality and social psychology, 52(6), 1061. doi:10.1037/0022-3514.52.6.1061

Silk, J.S., Steinberg, L., \& Morris, A.S. (2003). Adolescents' emotion regulation in daily life: Links to depressive symptoms and problem behavior. Child Development, 74(6), 18691880 .

Singer, J.A., Blagov, P., Berry, M., \& Oost, K.M. (2013). Self-defining memories, scripts, and the life story: Narrative identity in personality and psychotherapy. Journal of personality, 81(6), 569-582.

Slovic, P., Finucane, M. L., Peters, E., \& MacGregor, D. G. (2007). The affect heuristic. European journal of operational research, 177(3), 1333-1352. doi:10.1016/j.ejor.2005.04.006

Snyder, H.R., Gulley, L.D., Bijttebier, P., Hartman, C.A., Oldehinkel, A.J., Mezulis, A., Hankin, B.L. (2015). Adolescent emotionality and effortful control: Core latent constructs and links to psychopathology and functioning. Journal of Personality and Social Psychology, 109(6), 1132-1149. doi:10.1037/pspp0000047 
Sonnemans, J., Frijda, N.H. (1994). The structure of subjective emotional intensity. Cognition and Emotion, 8(4), 329-350. doi:10.1080/02699939408408945

Soto, C.J., John, O.P., Gosling, S.D., Potter, J. (2010). Age differences in personality traits from 10 to 65: Big five domains and facets in a large cross-sectional sample. Journal of Personality and Social Psychology, 100(2), 330-348. doi:10.1037/a0021717

Stanton, A. L., \& Low, C. A. (2012). Expressing Emotions in Stressful Contexts: Benefits, Moderators, and Mechanisms. Current Directions in Psychological Science, 21(2), 124128. doi: $10.1177 / 0963721411434978$

Suls, J., Martin, R. (2005). The daily life of the garden-variety neurotic: Reactivity, stressor exposure, mood spillover, and maladaptive coping. Journal of Personality, 73(6), 14851510. doi:10.1111/j.1467-6494.2005.00356.x

Tackett, J.L., Slobodskaya, H.R., Mar, R.A., Deal, J., Halverson, C.F., Jr., Baker, S.R., Pavlopoulos, V., Besevegis, E. (2012). The hierarchical structure of childhood personality in five countries: Continuity from early childhood to early adolescence. Journal of Personality, 80(4), 847-879. doi:10.1111/j.1467-6494.2011.00748.x

Thompson, R. A. (1994). Emotion regulation: A theme in search of definition. Monographs of the Society for Research in Child Development, 59, 25 -52. doi:10.2307/1166137

Tooby, J., \& Cosmides, L. (2008). The evolutionary psychology of the emotions and their relationship to internal regulatory variables. In: Lewis, M., Haviland-Jones, J.M., Barett, L.F. (Eds.), Handbook of emotions (3rd ed., pp. 114-137). New York: Guilford Press.

Trull, T.J., Lane, S.P., Koval, P., Ebner-Priemer, U.W. (2015). Affective dynamics in psychopathology. Emotion Review, 7(4), 355-361.

Van de Leemput, I.A., Wichers, M., Cramer, A.O.J., Borsboom, D., Tuerlinckx, F., Kuppens, P., Van Nes, E.H, Viechtbauer, W., Giltay, E.J., Aggen, S.H., Derom, C. (2013). Critical slowing down as early warning for the onset and termination of depression. Proceedings of the National Academy of Sciences, doi:10.1073/pnas.1312114110

Van der Krieke, L., Blaauw, F., Emerencia, A.C., Schenk, H.M., Slaets, J.P.J., Bos, E.H., de Jonge, P., Jeronimus, B.F. (2016). Temporal Dynamics of Health and Well-Being: A Crowdsourcing Approach to Momentary Assessments and Automated Generation of Personalized Feedback. Psychosomatic medicine, 79(2), 213-223. doi:10.1097/PSY.0000000000000378

Van der Krieke, L., Jeronimus, B.F., Blaauw, F.J., Wanders, R.B.K., Emerencia, A.C., Schenk, H.M., Vos, S.D., Snippe, E., Wichers, M., Wigman, J.T., Bos, E.H., Jonge, P.D. (2015). HowNutsAreTheDutch (HoeGekIsNL): A crowdsourcing study of mental symptoms and strengths. International Journal of Methods in Psychiatric Research, 25(2), 123-44. doi:10.1002/mpr.1495

Van der Maas, H.L.J., \& Molenaar, P.C.M. (1992). Stagewise cognitive development: An application of catastrophe theory. Psychological Review, 99(3), 395-417. doi:10.1037/0033-295X.99.3.395

Van der Stel, J. (2009). Psychopathologie: Grondslagen, determinanten, mechanismen. Amsterdam: Boom.

Van Geert, P., Steenbeek, H. (2005). Explaining after by before: Basic aspects of a dynamic systems approach to the study of development. Developmental review, 25(3), 308-442. doi:10.1016/j.dr.2005.10.003

Verduyn, P., Van Mechelen, I., \& Tuerlinckx, F. (2011). The relation between event processing and the duration of emotional experience. Emotion, 11(1), 20-28. doi: $10.1037 / \mathrm{a} 0021239$

Verduyn, P., \& Lavrijsen, S. (2015). Which emotions last longest and why: The role of event importance and rumination. Motivation and Emotion, 39(1), 119-127.

doi: 10.1007/s11031-014-9445-y 
Watson, D., Clark, L. A., \& Tellegen, A. (1988). Development and validation of brief measures of positive and negative affect: the PANAS scales. Journal of personality and social psychology, 54(6), 1063.

Watson, D., Gamez, W., Simms, L.J. (2005). Basic dimensions of temperament and their relation to anxiety and depression: A symptom-based perspective. Journal of Research in Personality, 39(1), 46-66.

Wichers, M., Groot, P.C., Psychosystems, ESM Group, EWS Group. (2016). Critical slowing down as a personalized early warning signal for depression. Psychotherapy and Psychosomatics, 85(2), 114-116. doi:10.1159/000441458

Wichers, M. (2014). The dynamic nature of depression: a new micro-level perspective of mental disorder that meets current challenges. Psychological medicine, 44(7), 1349-1360. doi:10.1017/S0033291713001979

Wichers, M., Wigman, J.T.W., Myin-Germeys, I. (2015). Micro-level affect dynamics in psychopathology viewed from complex dynamical system theory. Emotion Review, 7(4), 362-367. doi:10.1177/1754073915590623

Wichers, M., Schreuder, M.J., Goekoop, R., Groen, R.N. (2018). Can we predict the direction of sudden shifts in symptoms? Transdiagnostic implications from a complex systems perspective on psychopathology. Psychological medicine, 49(3), 380-387. doi:10.1017/S0033291718002064

Witherington, D.C. (2007). The dynamic systems approach as metatheory for developmental psychology. Human Development, 50(2-3), 127-153.

Wrzus, C., Roberts, B.W. (2017). Processes of personality development in adulthood: The TESSERA framework. Personality and Social Psychology Review, 21(3), 253-277. doi: $10.1177 / 1088868316652279$

Yang, X., Ram, N., Gest, S. D., Lydon-Staley, D. M., Conroy, D. E., Pincus, A. L., \& Molenaar, P. (2018). Socioemotional Dynamics of Emotion Regulation and Depressive Symptoms: A Person-Specific Network Approach. Complexity, 2018. doi: $10.1155 / 2018 / 5094179$

Yik, M., Russell, J. A., \& Steiger, J. H. (2011). A 12-point circumplex structure of core affect. Emotion, 11(4), 705. doi:10.1037/a0023980

Zahn-Waxler, C., Klimes-Dougan, B., Slattery, M.J. (2000). Internalizing problems of childhood and adolescence: Prospects, pitfalls, and progress in understanding the development of anxiety and depression. Development and Psychopathology, 12(3), 443 466. doi: 10.1017/S0954579400003102 